\title{
Evidence for Modulation of Substance Use Disorders by the Gut Microbiome: Hidden in Plain Sight
}

\author{
Mariana Angoa-Pérez and Donald M. Kuhn \\ Research and Development Service, John D. Dingell VA Medical Center, and Department of Psychiatry and Behavioral Neurosciences, \\ Wayne State University School of Medicine, Detroit, Michigan
}

Abstract. ..................................................................... 571

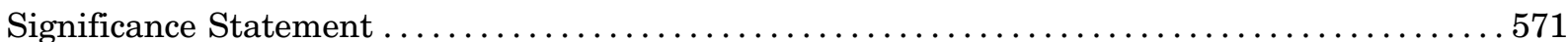

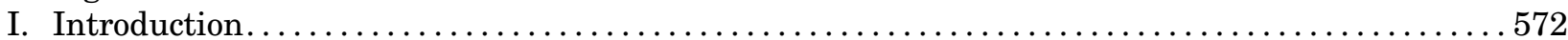

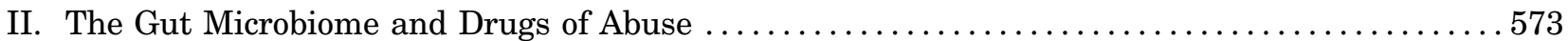

III. CTX and Other Antibiotics ................................................. 574

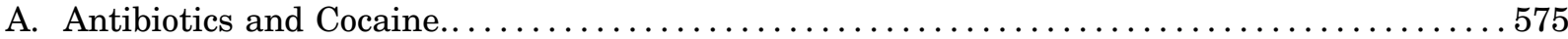

B. Antibiotics and Alcohol. ............................................... 577

C. Antibiotics and Opiates................................................ 577

D. Antibiotics and Methamphetamine, Amphetamine, and Nicotine................. 577

E. Summary and Alternative Interpretations of Studies Examining Effects of Antibiotics

on the Rewarding Effects of Drugs of Abuse............................... 577

IV. Sodium Butyrate, Histone Deacetylase Enzymes, and Drugs of Abuse ................ 582

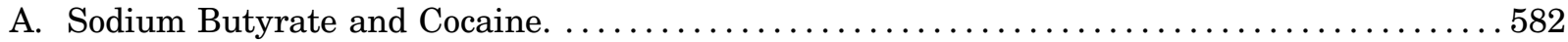

B. Sodium Butyrate and Alcohol......................................... 583

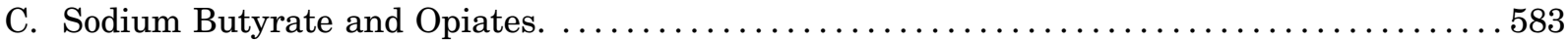

D. Sodium Butyrate and Methamphetamine, Amphetamine, and Nicotine ............. 583

E. Summary and Alternative Interpretations of Studies Examining Effects of Sodium

Butyrate on the Rewarding Effects of Drugs of Abuse. ........................ 583

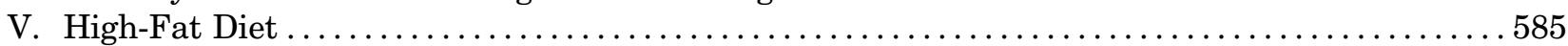

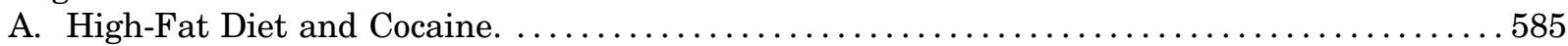

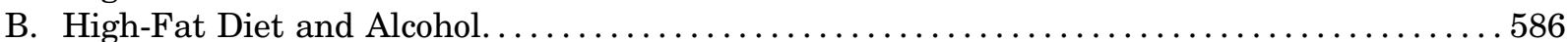

C. High-Fat Diet and Opiates............................................. 586

D. High-Fat Diet and Methamphetamine, Amphetamine, and Nicotine. ................ 586

E. Summary and Alternative Interpretations of Studies Examining Effects of High-Fat

Diet on the Rewarding Effects of Drugs of Abuse............................... 588

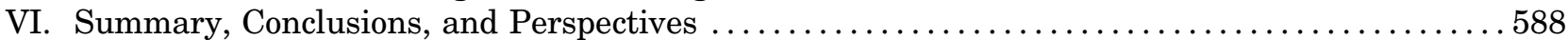

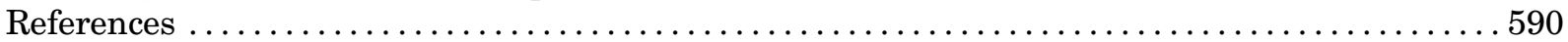

\begin{abstract}
The gut microbiome modulates neurochemical function and behavior and has been implicated in numerous central nervous system (CNS) diseases, including developmental, neurodegenerative, and psychiatric disorders. Substance use disorders (SUDs) remain a serious threat to the public wellbeing, yet gut microbiome involvement in drug abuse has received very little attention. Studies of the mechanisms underlying SUDs have naturally focused
\end{abstract}

on CNS reward circuits. However, a significant body of research has accumulated over the past decade that has unwittingly provided strong support for gut microbiome participation in drug reward. $\beta$-Lactam antibiotics have been employed to increase glutamate transporter expression to reverse relapse-induced release of glutamate. Sodium butyrate has been used as a histone deacetylase inhibitor to prevent druginduced epigenetic alterations. High-fat diets have

Address correspondence to: Dr. Donald M. Kuhn, Department of Psychiatry and Behavioral Neurosciences, Wayne State University School of Medicine, 4646 John R, Detroit, MI. E-mail: donald.kuhn@wayne.edu

This work was supported by the Department of Veterans Affairs [Grant IK6RX002419].

The authors declare no financial conflicts.

https://doi.org/10.1124/pharmrev.120.000144. 
been used to alter drug reward because of the extensive overlap of the circuitry mediating them. This review article casts these approaches in a different light and makes a compelling case for gut microbiome modulation of SUDs. Few factors alter the structure and composition of the gut microbiome more than antibiotics and a highfat diet, and butyrate is an endogenous product of bacterial fermentation. Drugs such as cocaine, alcohol, opiates, and psychostimulants also modify the gut microbiome. Therefore, their effects must be viewed on a complex background of cotreatment-induced dysbiosis. Consideration of the gut microbiome in SUDs should have the beneficial effects of expanding the understanding of SUDs and aiding in the design of new therapies based on opposing the effects of

\section{Introduction}

According to the National Survey on Drug Use and Health, approximately 20 million American adults had a substance use disorder (SUD) in 2017. The National Institute on Drug Abuse has estimated that abuse of tobacco, alcohol, and illicit drugs costs the nation $\sim \$ 740$ billion annually in expenses related to crime, lost work productivity, and health care (see following link on National Institute on Drug Abuse webpage: https:// www.drugabuse.gov/drug-topics/trends-statistics/costssubstance-abuse). Therefore, SUDs constitute a serious threat to the public well-being. A great deal of research has been focused on achieving a better understanding of the mechanisms by which abused drugs exert their addictive properties to develop more effective treatments. Unfortunately, Food and Drug Administration-approved therapies for SUD at present remain limited to methadone, buprenorphine, and extended-release naloxone for treatment of opiate use disorder. The vast majority of research on the mechanisms underlying SUDs has focused on reward pathways in the brain and, more specifically, the circuits in the ventral tegmentum area (VTA) and nucleus accumbens (NAc) that are activated by drugs of abuse and use the neurotransmitters dopamine (DA) and glutamate for synaptic signaling. A better understanding of the central nervous system (CNS) sites that are hijacked by alcohol, tobacco, and illicit drugs would possibly lead to new treatment strategies for SUDs.

By focusing almost entirely on CNS mechanisms underlying SUDs, other possible mediators outside of the CNS may escape notice, thus remaining understudied and underappreciated. Emerging results provide evidence of peripheral mechanisms that can mediate complex reward-seeking behaviors previously abused drugs on the host's commensal bacterial community.

Significance Statement-Proposed mechanisms underlying substance use disorders fail to acknowledge the impact of drugs of abuse on the gut microbiome. $\beta$-Lactam antibiotics, sodium butyrate, and high-fat diets are used to modify drug seeking and reward, overlooking the notable capacity of these treatments to alter the gut microbiome. This review aims to stimulate research on substance abuse-gut microbiome interactions by illustrating how drugs of abuse share with antibiotics, sodium butyrate, and fatladen diets the ability to modify the host microbial community. assigned to the CNS. The pioneering research of Hoebel and colleagues provided some of the earliest evidence that bingeing on sugar solutions has effects that are similar to substance abuse in that it shows dependenceand withdrawal-like behaviors, it cross-sensitizes with amphetamine, and it releases DA in the NAc [reviewed in Avena et al. (2008, 2009, 2011)]. Additionally, de Araujo and colleagues have shown that gut stimulation with caloric nutrients induces robust striatal DA release (Ren et al., 2010; de Araujo et al., 2012; Ferreira et al., 2012). Mice fed high-fat diets do not show the caloriedependent DA effluxes seen in mice fed low-fat diets and this high-fat-induced DA deficiency is restored by the dietary satiety messenger oleoylethanolamine (Tellez et al., 2013). More recently, these same investigators have identified the neural circuit for gut-induced reward by showing that optical activation of the right nodose ganglion causes release of DA in the striatum, sustains self-stimulation behavior, and conditions a place preference [conditioned place preference (CPP)] that maps to populations of well known reward neurons in the nigro-striatal pathway (Han et al., 2018). In a related study, Fernandes et al. (2020) demonstrated that the intragastric administration of sucrose sustains self-administration and increases the activity of VTADA neurons via the hepatic branch of the vagus nerve. These investigators also showed that optogenetic stimulation of the left nodose ganglion significantly increased the activity of VTA-DA neurons (Fernandes et al., 2020). These findings suggest that nutrients can exert effects that are reminiscent of the actions of drugs of abuse, such as ethanol and nicotine, which have been shown to directly increase the firing of VTA neurons (Juarez and Han, 2016), and also maintain self-administration and support development of a CPP. The notion that compulsive intake of drugs and food share neurobiological

ABBREVIATIONS: CLV, clavulanic acid; CNS, central nervous system; CPP, conditioned place preference; CTX, ceftriaxone; DA, dopamine; $\mathrm{DA} \mathrm{D}_{1} \mathrm{R}, \mathrm{DA} \mathrm{D}_{1}$ receptor; DA $\mathrm{D}_{2} \mathrm{R}, \mathrm{DA} \mathrm{D}_{2}$ receptor; DAT, DA transporter; DOX, doxycycline; GHSR1a, growth hormone secretagogue receptor type 1a; GI, gastrointestinal; GLT1, glutamate transporter 1; HDAC, histone deacetylase; HFD, high-fat diet; mGluR2, metabotropic glutamate receptor 2; MINO, minocycline; NaB, sodium butyrate; NAc, nucleus accumbens; NIDA, National Institute on Drug Abuse; OM, Osborne-Mendel; Per1, period circadian regulator 1; SCFA, short-chain fatty acid; SUD, substance use disorder; TIG, tigecycline; VTA, ventral tegmentum area. 
substrates, which involve impairments in DA pathways regulating reward sensitivity and incentive motivation, has long been debated, and supportive data have been reviewed (Volkow and Wise, 2005; Gregorowski et al., 2013; Volkow et al., 2013; Clasen et al., 2020a). More recently, it has emerged that non-nutritive drugs of abuse (e.g., cocaine, amphetamine) can directly influence neuronal activity in homeostatic feeding circuits (i.e., Agouti-related protein neurons of the arcuate nucleus of the hypothalamus) and increase mesoaccumbal DA signaling (Alhadeff et al., 2019). Betley and colleagues propose the coordination of hypothalamic Agouti-related neuropeptide neurons and midbrain DA circuits to form reciprocal networks in the modulation of the neural processing of rewards (Alhadeff et al., 2019) and affirm the close interplay between the compulsive intake of food and drugs of abuse.

Wise and Kiyatkin (2011) have provided evidence for peripheral input to the addictive properties of cocaine that do not involve feeding-reward circuits. These investigators hypothesized that the peripheral actions of cocaine can serve as conditioned interoceptive stimuli for the central actions of this psychostimulant (Wise and Kiyatkin, 2011). Using cocaine methiodide, a quaternary cocaine analog that does not cross the bloodbrain barrier, they demonstrated that central DA and glutamate release can be elicited by the methiodide analog in rats previously trained to self-administer cocaine $\mathrm{HCl}$ but not in naïve rats (Wise et al., 2008; Wang et al., 2013; Wakabayashi and Kiyatkin, 2014). Cocaine methiodide forms a $\mathrm{CPP}$ in cocaine $\mathrm{HCl}$ experienced rats and reinstates lever pressing after extinction of cocaine $\mathrm{HCl}$ self-administration (Wang et al., 2013).

Taken together, the foregoing discussion establishes rationale for the operation of peripheral input into the central actions of addictive drugs. The close interplay between neural circuits for the rewarding properties of nutrients (i.e., fat and sugar) and drugs of abuse raises the possibility that the gut microbiome and the gut-brain axis may also be involved in SUDs. The purpose of this commentary therefore is to discuss a wealth of published information that implicates the gut microbiome in SUDs but without invoking a role for it. The schematic in Fig. 1 illustrates the main discussion points of this review. Although discussion of the gut-brain axis per se is beyond the scope of this overview, the interested reader is referred to numerous, excellent review articles on this subject (Cryan and O'Mahony, 2011; Mayer, 2011; Carabotti et al., 2015; Mayer et al., 2015; Dinan and Cryan, 2017; Cryan et al., 2019).

\section{The Gut Microbiome and Drugs of Abuse}

The bulk of the microbiome resides in the gastrointestinal (GI) tract and is composed of bacteria, microbes, viruses, and archaea. It has been estimated that the human GI system contains $>1000$ bacterial species and $\sim 4 \times 10^{13}$ microorganisms [same as number of human cells (Sender et al., 2016)], and gut microbiome expresses $\sim 100$ times as many genes as the host human genome (Savage, 1977; Hamady and Knight, 2009). Normal functioning of the gut microbiome is essential to the maintenance of human health. A disruption in the gut microbiome composition (i.e., dysbiosis) has been linked to numerous diseases, including cancer, diabetes, obesity, immune dysfunction, and inflammatory bowel disease (Pflughoeft and Versalovic, 2012; Shreiner et al., 2015). It is also emerging that gut microbiome dysbiosis can play a role in numerous neurologic [e.g., Parkinson disease, Alzheimer disease (Tremlett et al., 2017)] and psychiatric diseases [e.g., autism (Dinan and Cryan, 2017), depression, and anxiety (Foster and McVey Neufeld, 2013)] and in eating disorders (Seitz et al., 2019).

Research on gut microbiome involvement in SUDs lags well behind most other health disorders, but an increasing number of publications are documenting drug-induced alterations in it. Many drugs of abuse are well known to alter GI function through gut microbiome modifications, and examples of this include opiate-induced constipation (Nee et al., 2018) and cocaine-induced bowel ischemia (Riezzo et al., 2012). It is therefore relevant to opiate use that constipation causes gut dysbiosis, and treatments that relieve constipation (e.g., probiotics) restore changes in the gut microbiome caused by this bowel condition (Dimidi et al., 2017; Meng et al., 2020). With regard to cocaine, modulation of the gut microbiome can prevent intestinal ischemia/reperfusion injury (Yoshiya et al., 2011; Bertacco et al., 2017). Alcohol (Caton et al., 2015), cocaine (Billing and Ersche, 2015), and amphetamine (Lemieux et al., 2015) can significantly alter the appetite as well. In view of the profound effects that diet has on the gut microbiome (Singh et al., 2017; Hills et al., 2019; Ezra-Nevo et al., 2020; Wilson et al., 2020), it should come as no surprise that many drugs of abuse can disrupt the composition of the gut microbiome.

The greatest amount of progress in SUD-gut microbiome interactions has been made for alcohol. It is now known that the gut microbiome is significantly altered in humans after moderate consumption (Kosnicki et al., 2019; Stadlbauer et al., 2019) as well as in those with alcohol dependence (Mutlu et al., 2012; Leclercq et al., 2014; Dubinkina et al., 2017; Bjørkhaug et al., 2019). Chronic alcohol consumption changes the composition of the gut microbiome of nonhuman primates (Barr et al., 2018; Zhang et al., 2019b) and alters microbiome status in rodent models of alcohol seeking (Peterson et al., 2017; Jadhav et al., 2018), chronic consumption (Yan et al., 2011; Bull-Otterson et al., 2013; Labrecque et al., 2015; Fan et al., 2018; Wang et al., 2018b; Kosnicki et al., 2019; Xu et al., 2019; Bluemel et al., 2020), 


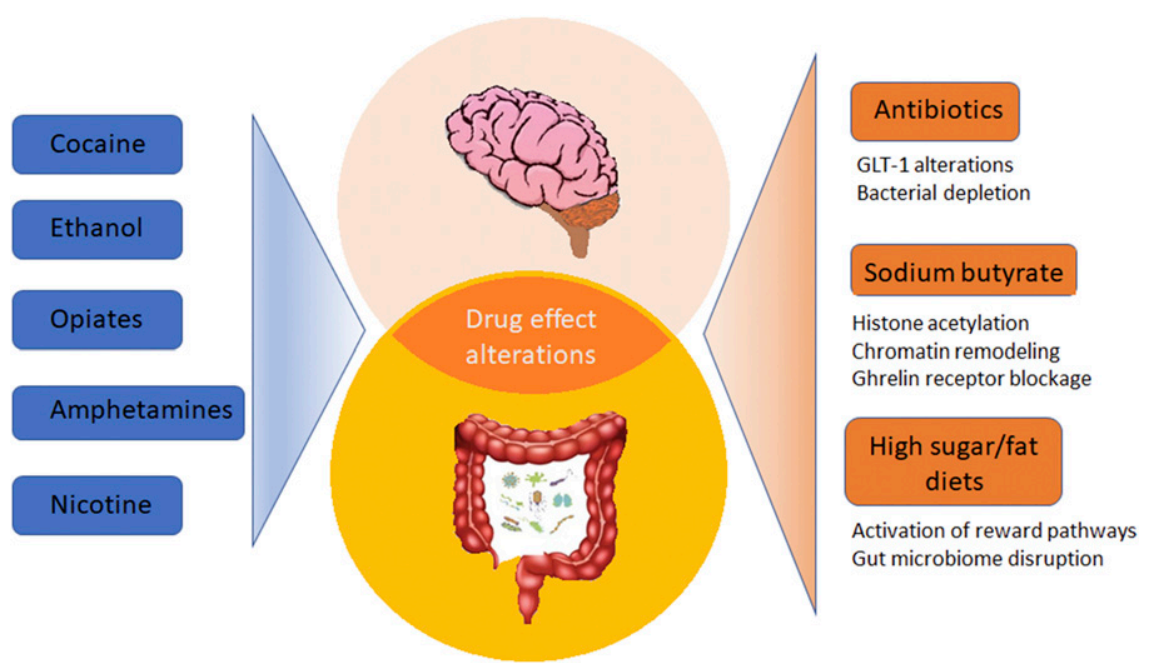

Fig. 1. Potential interactions between the brain and the gut microbiome in the modulation of the rewarding effects of drugs of abuse. Cocaine, ethanol, opiates, and psychostimulants have been shown to modify the gut microbiome. Beyond their suspected actions on the brain, $\beta$-lactam antibiotics, sodium butyrate, and hyperpalatable diets are also potent modifiers of the composition of the microbial communities in the gut. Studies on the mechanisms underlying substance use disorders have focused on CNS mechanisms, but the possibility exists for modulation of drug reward by the gut microbiome. This review offers alternative interpretations of research that has used antibiotics, sodium butyrate, and high-fat diets to modify drug reward and relapse by highlighting the profound effects of these agents on the gut microbiome. It is now clear that drugs of abuse cause significant alterations in the gut microbiome. Antibiotics, sodium butyrate, and high-fat diets also modify the gut microbiome. Therefore, when antibiotics, for example, are tested for effects on cocaine reward and relapse, consideration should be given to the possibility that the outcomes reflect the combined influence of both treatments on the gut microbiome.

and withdrawal (Xiao et al., 2018). Alcohol-induced dysbiosis has even been the subject of numerous review articles (Engen et al., 2015; Hillemacher et al., 2018; Leclercq et al., 2019; Qamar et al., 2019; Temko et al., 2017). With regard to opiates, chronic use is associated with substantial alterations in the gut microbiome of humans (Acharya et al., 2017; Xu et al., 2017) and nonhuman primates (Sindberg et al., 2019). Similarly, animal models of opiate dependence (Banerjee et al., 2016; Lee et al., 2018; Wang et al., 2018a, 2020) and analgesic tolerance (Kang et al., 2017; Zhang et al., 2019a) document drug-induced alterations in the gut microbiome. The effects of opiates on the microbiome have been the subject of several review articles as well (Akbarali et al., 2014; Akbarali and Dewey, 2017; Wang and Roy, 2017; Le Bastard et al., 2018; Wiss, 2019; Ren and Lotfipour, 2020). Emerging results have shown that cocaine causes dysbiosis in the gut microbiome of humans (Volpe et al., 2014) and rodents (Chivero et al., 2019; Scorza et al., 2019). Depletion of gut bacteria by treatment with a prolonged course of antibiotics increased sensitivity to cocaine CPP and enhanced its locomotor-stimulating properties (Kiraly et al., 2016). Nicotine (Allais et al., 2016; Chi et al., 2017; Wang et al., 2019; Nolan-Kenney et al., 2020), methamphetamine (Angoa-Pérez et al., 2020; Ning et al., 2017; Xu et al., 2017), bath-salts drugs (Angoa-Pérez et al., 2020), and cannabinoids (Al-Ghezi et al., 2019; Cluny et al., 2015) also cause significant dysbiosis in the gut microbiome. The effects of selected drugs of abuse on the gut microbiome have been reviewed recently (Meckel and Kiraly, 2019).
The first crucial step in assessing how drugs of abuse interact with the gut microbiome (e.g., documentation of drug-induced alterations in its composition and structure) has been partially achieved via the studies cited in the previous paragraph, but much work and many opportunities remain in this area. The next step involves determination of whether the gut microbiome modulates or plays active roles in SUDs. This second step has begun via studies that have used ceftriaxone (CTX), sodium butyrate (NaB), and high-fat diets (HFDs) to alter responses to a drug of abuse. However, these treatments were used for reasons completely unrelated to their ability to interact with the gut microbiome. These factors and the rationale for their use will be discussed below for cocaine, alcohol, opiates, and other drugs of abuse (e.g., methamphetamine, amphetamine, nicotine).

\section{CTX and Other Antibiotics}

CTX is a third-generation broad-spectrum $\beta$-lactam antibiotic. Its recruitment into studies of drugs of abuse was stimulated by a 2005 publication showing that CTX and other $\beta$-lactam antibiotics caused increases in the CNS expression of the glutamate transporter 1 [GLT1; (Rothstein et al., 2005)]. Rothstein and colleagues (2005) documented the ability of $\beta$-lactam drugs to increase transcription of the GLT1 gene in both in vitro and in vivo experiments and demonstrated that CTX was neuroprotective in the G93A-SOD1 mouse model of amyotrophic lateral sclerosis. CTX was deemed neuroprotective by virtue of its ability to increase the reuptake of the excitatory neurotransmitter glutamate 
via GLT1 and thereby reduce glutamate excitotoxicity (Rothstein et al., 2005). Beginning a few years after this publication and continuing to the present, a large number of studies have used CTX to modulate the rewarding effects of drugs of abuse, using it to increase expression of GLT1. It had already been demonstrated in a series of elegant studies that relapse to drug self-administration after extinction is mediated by downregulation of the GLT1 with a resulting increased secretion of glutamate in the NAc. The glutamate theory of addiction has been thoroughly discussed in numerous reviews (Koob and Nestler, 1997; Kalivas, 2004, 2009; Kalivas et al., 2009; Knackstedt and Kalivas, 2009; Torregrossa and Kalivas, 2008; Shen et al., 2014; Koob and Volkow, 2016; Spencer et al., 2016; Scofield, 2018). When using CTX strictly for its ability to increase expression of GLT1, the primary pharmacological action of this drug is overlooked. CTX is, after all, a powerful antibiotic that inhibits a large number of bacterial pathways. Two population-based metagenomics analyses revealed that use of antibiotics was significantly associated with alterations in microbiome composition, and the only drugs significantly associated with the differential abundance of specific bacterial genera were $\beta$-lactam antibiotics (Falony et al., 2016; Zhernakova et al., 2016). A recent review (Ferrer et al., 2017) illustrates the extremely broad effects of CTX and other $\beta$-lactams on the gut microbiome. CTX in particular alters nine different bacterial genera throughout the phyla of Actinobacteria, Bacteroidetes, Firmicutes, and Verrucomicrobia (Ferrer et al., 2017). Other antibiotics used to modify the addictive properties of drugs of abuse include primarily the $\beta$-lactams clavulanic acid (CLV), cefazolin, cefoperazone, ampicillin, and amoxicillin. The combination of CLV with amoxicillin (i.e., Augmentin) has also been used. CLV requires additional emphasis because it is stated to have minimal antimicrobial activity (and for this reason it is often combined with amoxicillin clinically), yet it retains the $\beta$-lactam moiety necessary to increase GLT1 expression (Rothstein et al., 2005). Therefore, when used by itself to alter the actions of a drug of abuse, CLV effects are generally attributed solely to alterations in GLT1. Despite this interpretation, CLV does have antimicrobial activity (Finlay et al., 2003; Ferrer et al., 2017) and has been linked to alterations in numerous bacterial genera within the phyla of Actinobacteria, Firmicutes, and Proteobacteria (Ferrer et al., 2017). The tetracycline derivatives minocycline (MINO), tigecycline (TIG), and doxycycline (DOX) have also been used in this regard. These latter drugs, like CTX, have broad effects on the gut microbiome (Wong et al., 2016; Ferrer et al., 2017; Hasebe et al., 2019; Schmidtner et al., 2019; Leigh et al., 2020). In general, the tetracyclines are used in studies of drugs of abuse for their anti-inflammatory properties via blockade of microglial activation and inhibition of matrix metallopeptidases, cyclooxygenase-2, protein kinase $\mathrm{C}$, phospholipase A2, and/or nitric oxide synthase (Garrido-Mesa et al., 2013), although these drugs are by no means specific for acting on microglia (Möller et al., 2016). The antibiotic effects of $\beta$-lactams and tetracycline derivatives on bacteria in turn can lead to significant alterations in gut microbial activity and gene and protein expression, microbiome metabolite content (long linear and branched-chain fatty acids, saturated and unsaturated fatty acids), branched-chain amino acids, sugars, peptides, and polyamines (Willing et al., 2011; Pérez-Cobas et al., 2013; Becattini et al., 2016; Zhang and Chen, 2019). These alterations in the gut microbiome, many of which are adverse to the host, could then reverberate into the CNS via the gutbrain axis.

A. Antibiotics and Cocaine. A large number of studies have examined CTX for its ability to alter the addictive properties of cocaine. These publications are highlighted in Table 1 . The general experimental approach in the majority of these preclinical studies is to establish consistent self-administration of cocaine, which is then extinguished, and CTX is given at the start of cue-primed reinstatement of cocaine selfadministration. Some investigators have also used the CPP and the locomotor sensitization models. Most of these studies highlighted in Table 1 document that CTX and other $\beta$-lactam antibiotics, such as ampicillin and CLV, indeed decrease reinstatement of cocaine seeking after extinction of self-administration. It has been reported that CTX decreases the reinforcing efficacy of cocaine (Kim et al., 2016). Although some of these studies showed that CTX increased GLT1 expression and function, some did not. None of the studies in Table 1 mentioned the potential effects of CTX-induced alterations in the gut microbiome. Nonetheless, several of these papers do present data that open the results on CTX and cocaine reinstatement to alternative interpretations. One study showed that increases in GLT1 expression using a viral vector harboring the GLT1 construct reduced glutamate efflux but did not block cocaine reinstatement (Logan et al., 2018). Another study showed that amoxicillin reduced cocaine seeking after cue-primed reinstatement without increasing expression of GLT1. CLV did not reduce cocaine seeking under cue-primed reinstatement but did restore GLT1 levels in the NAc versus the cocaine-induced reduction in this protein (Bechard et al., 2019). A third study tested CTX to block cocaine reinstatement in rats trained to self-administer cocaine alone or cocaine plus alcohol (Stennett et al., 2020). These investigators made the interesting observation that CTX attenuated relapse in the cocaine-only group but not in the cocaine + alcohol group, but the latter treatment group showed increased GLT1 expression in the NAc (Stennett et al., 2020). Focus on the GLT1 in mediating CTX-induced prevention of cue-induced relapse to cocaine self-administration has 


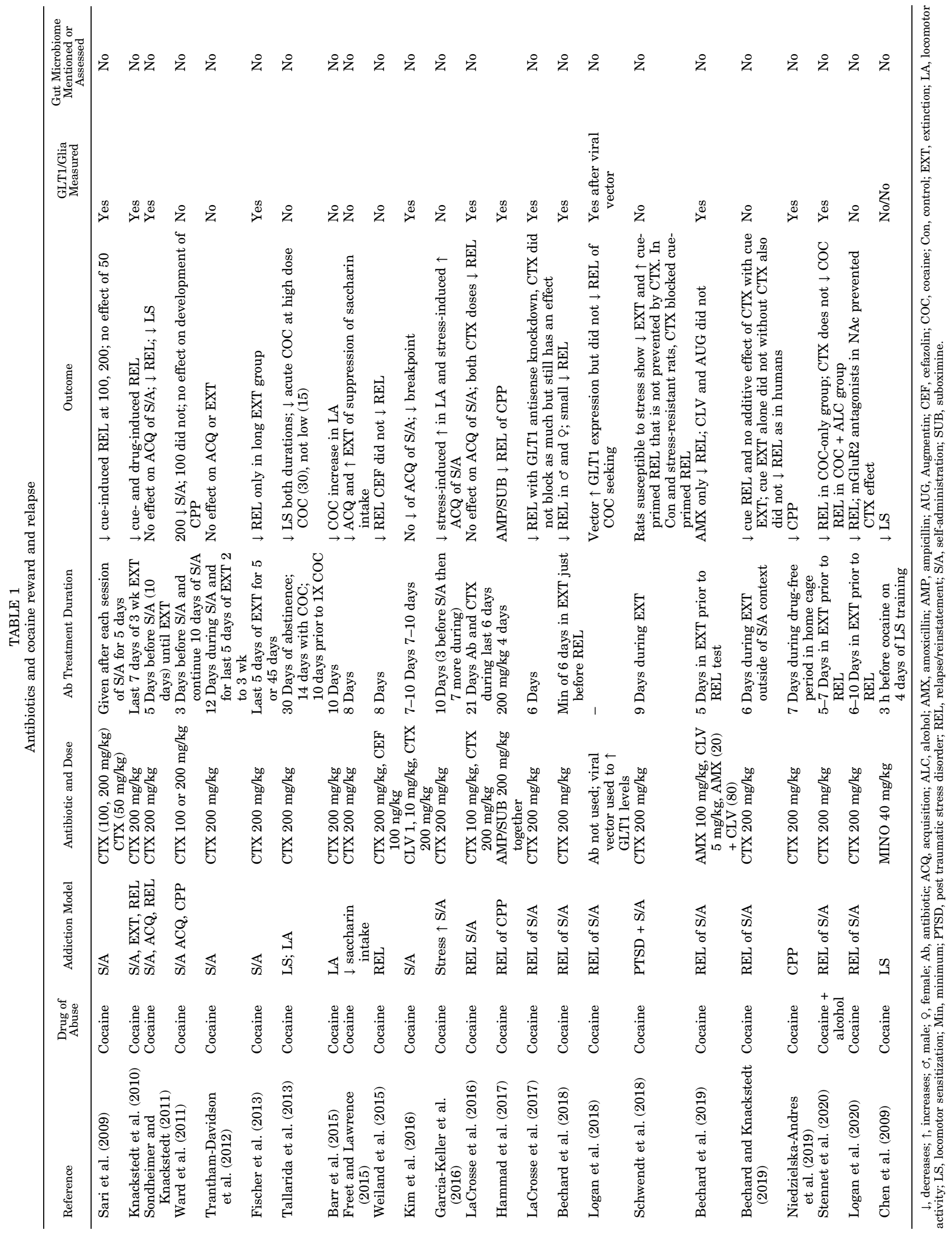


shifted somewhat to the metabotropic glutamate receptor 2 (mGluR2) after the demonstration that the mGluR2 antagonist LY341495 injected directly into the NAc prevented CTX from attenuating reinstatement of cocaine seeking (Logan et al., 2020). Finally, cefazolin was found not to reduce cocaine reinstatement (Weiland et al., 2015). MINO prevents the development of cocaine locomotor sensitization (Chen et al., 2009) as is seen with CTX (Sondheimer and Knackstedt, 2011).

B. Antibiotics and Alcohol. CTX has been used in studies with alcohol to increase GLT1 expression in the same manner used to reduce cocaine reward. Most studies examining the effects of CTX on alcohol have used alcohol-preferring rats that are exposed to voluntary alcohol drinking for times ranging from 5 to 14 weeks. Thereafter, CTX (or another antibiotic) is given for 5-7 days in the first or second week after chronic drinking, and intake is measured for the remainder of the experiment. This approach is referred to as relapselike drinking and has been used effectively by Sari and colleagues. Publications reporting alcohol-antibiotic interactions are highlighted in Table 2. The literature is in good agreement in showing that CTX reduces relapse-like drinking (Sari et al., 2011, 2013a,b, 2016; Qrunfleh et al., 2013; Alhaddad et al., 2014; Rao and Sari, 2014a,b; Das et al., 2015; Rao et al., 2015c; Stennett et al., 2017). Ampicillin, cefazolin, cefoperazone, CLV, amoxicillin, and Augmentin share with CTX the ability to reduce relapse-like drinking (Goodwani et al., 2015; Hakami et al., 2017; Hakami and Sari, 2017; Rao et al., 2015b). In addition, CTX blocks acquisition of alcohol intake (Sari et al., 2013a) and attenuates alcohol withdrawal syndrome (Abulseoud et al., 2014). CTX and cefazolin also attenuate cueprimed reinstatement of alcohol drinking using an operant approach (Weiland et al., 2015). The majority of the studies referenced in Table 2 confirmed antibiotic-induced increases in expression of GLT1, with some interesting exceptions (see below). A smaller number of studies have tested various tetracycline derivatives, and despite the fact that these drugs were used for their ability to block microglial activation and reduce neuroinflammation, none of these effects were documented. When given before alcohol, MINO, TIG, and DOX significantly reduce voluntary drinking (Agrawal et al., 2011; Bergeson et al., 2016; Syapin et al., 2016). MINO also blocks alcohol reward as assessed by CPP (Gajbhiye et al., 2017), and both MINO and TIG reduce alcohol withdrawal (Martinez et al., 2016; Gajbhiye et al., 2018). A number of reviews have been published on CTX-GLT1-alcohol dependence interactions (Rao and Sari, 2012; Sari, 2013; Rao et al., 2015a; Bell et al., 2017).

C. Antibiotics and Opiates. A relatively small number of studies have investigated the interactions between antibiotics and opiates, and these papers are highlighted in Table 3. Early studies established that
CTX attenuates morphine dependence, analgesic tolerance, and precipitated withdrawal (Rawls et al., 2010a,b; Habibi-Asl et al., 2014) and inhibits the development of morphine hyperalgesia (Chen et al., 2012). Other investigations determined that CTX and CLV decreased acquisition and/or reinstatement of a morphine (Schroeder et al., 2014; Mehri et al., 2018) or hydrocodone CPP (Alshehri et al., 2018), whereas another study reported that CTX alone did not alter acquisition and reinstatement of a morphine CPP (Fan et al., 2012). Finally, it has been reported that CTX prevented cue-induced heroin seeking (Shen et al., 2014). Most of these studies did not confirm altered expression of GLT1, but the paper of Shen et al. (2014) did provide an extensive investigation of $N$-methyl-daspartate receptor electrophysiology that documented increased glutamate uptake after CTX treatment. One study did establish CTX-mediated increases in GLT1 expression (Chen et al., 2012), and another reported that CTX decreased reinstatement of an opiate CPP without increasing GLT1 expression (Alshehri et al., 2018). MINO has been shown to decrease (Hutchinson et al., 2008) and facilitate extinction and reduce reinstatement of the morphine CPP (Arezoomandan and Haghparast, 2016). MINO also delays the development of morphine analgesic tolerance but does not reverse existing tolerance in rats with neuropathic pain (Zhang et al., 2015).

D. Antibiotics and Methamphetamine, Amphetamine, and Nicotine. A few of studies have investigated the effects of antibiotics on dependence-like behaviors associated with methamphetamine, amphetamine, and nicotine, and these are highlighted in Table 4. Both CTX (Abulseoud et al., 2012) and CLV (Althobaiti et al., 2019) reduce reinstatement of the extinguished methamphetamine CPP. CTX also reduces cue-primed reinstatement of amphetamine self-administration (Garcia et al., 2019) and decreases amphetamine-induced behavioral sensitization (Rasmussen et al., 2011). MINO reduces the formation and reinstatement of a methamphetamine CPP (Fujita et al., 2012; Attarzadeh-Yazdi et al., 2014) and also reduces methamphetamine selfadministration (Snider et al., 2013). In humans, MINO reduces the subjective effects of amphetamine but does not alter amphetamine choice (Sofuoglu et al., 2011). With regard to nicotine, CTX reduces the development of nicotine analgesic tolerance (Schroeder et al., 2011), attenuates the persistence of a nicotine CPP (Philogene-Khalid et al., 2017), and reduces its reinstatement (Alajaji et al., 2013). Finally, MINO has been shown to reduce craving for cigarettes in humans, but it does not alter smoking self-administration or the subjective responses to intravenous nicotine (Sofuoglu et al., 2009).

E. Summary and Alternative Interpretations of Studies Examining Effects of Antibiotics on the Rewarding Effects of Drugs of Abuse. The interpretation 


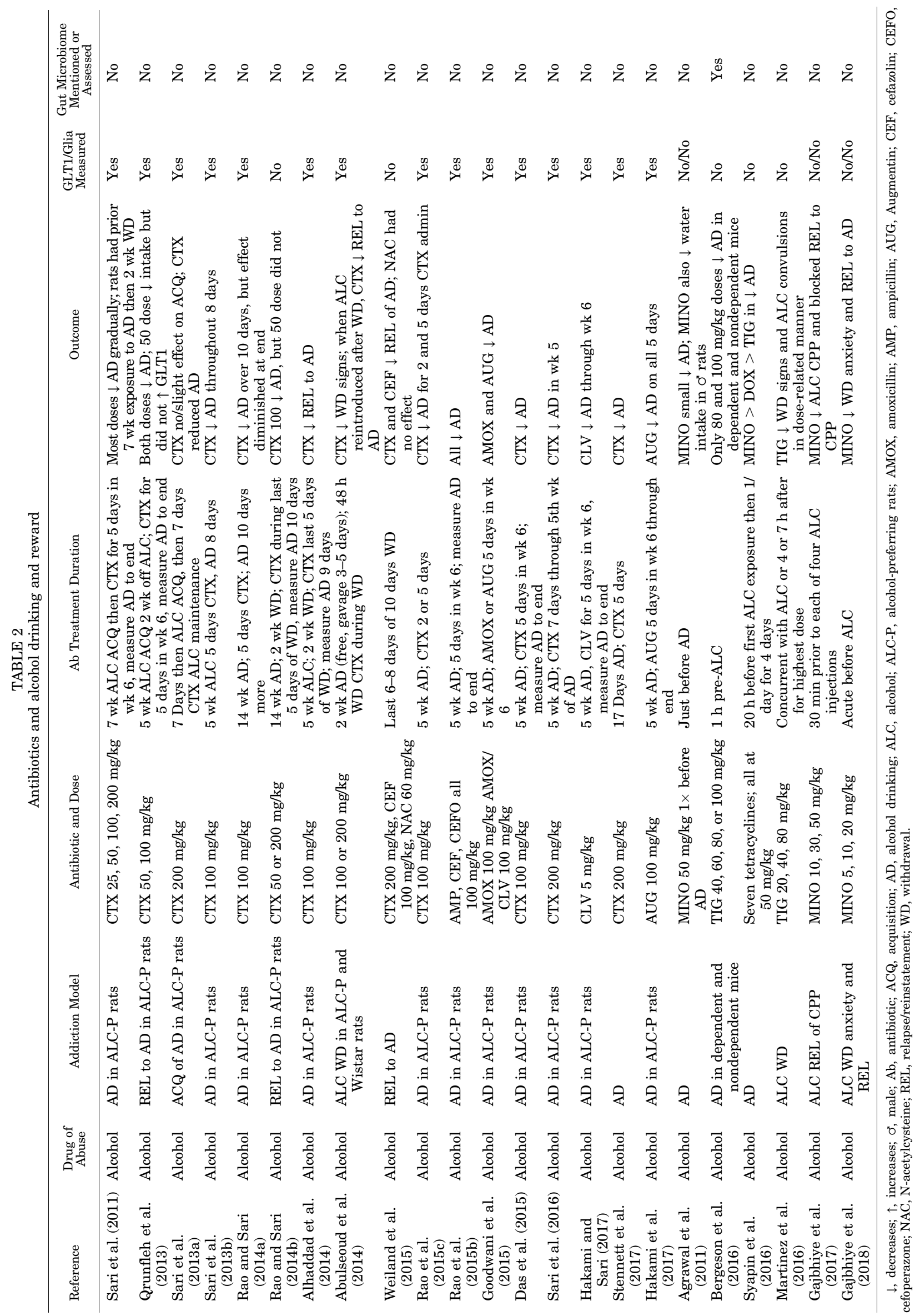


of results from the vast majority of studies of antibiotic interactions with drugs of abuse focuses on $\beta$-lactams for the ability to increase expression of GLT1 and on tetracyclines for their ability to reduce microglial activation and neuroinflammation. Often, neither of these purported effects was confirmed. However, the outcomes of the studies in this section leave open the possibility that the gut microbiome is involved in antibiotic-induced reward reduction for the following reasons:

1. All drugs of abuse considered in the foregoing section cause significant disruptions in the gut microbiome.

2. CTX can increase expression of the GLT1, but MINO does not, yet both can alter the rewarding effects of drugs of abuse. Although CTX and MINO may influence drug reward via different CNS actions, both have antimicrobial properties and effects that have not been considered in data interpretation. In fact, the common property shared by all antibiotics discussed above is the ability to knock down the gut microbiome. Even CLV, which retains the $\beta$-lactam moiety required to increase GLT1 expression but reportedly has minimal antimicrobial activity, does indeed have antibacterial actions (Finlay et al., 2003; Ferrer et al., 2017). Therefore, all antibiotics alter the gut microbiome, and their varying effects on the rewarding properties of drugs of abuse may be explained by the specific pattern by which they do so. It is also significant that antibiotics are administered on a background of drug-induced disturbances in the gut microbiome. The possibility of gut microbiome involvement in the actions of antibiotics was acknowledged by only one study highlighted in Table 2. Although the study by Bergeson et al. (2016) showed TIGmediated reduction in alcohol intake, a role for the gut microbiome was discounted because of the short duration of antibiotic treatment ( 1 hour prior to alcohol), and a mechanism was not posited to explain this antibiotic-induced reduction of alcohol intake.

3. Assuming that CTX-induced increases in GLT1 expression are the mechanism by which drug reward is blocked, a significant dissociation exists between GLT1 expression and reward reduction. This discrepancy exists in studies of cocaine (Logan et al., 2018; Bechard et al., 2019; Stennett et al., 2020), wherein antibiotics may or may not alter GLT1 expression and/or cocaine reward. With regard to alcohol, Qrunfleh et al. (2013) showed that although CTX doses of 50 and $100 \mathrm{mg} / \mathrm{kg}$ both significantly reduced relapselike drinking of alcohol, only the higher dose increased GLT1 levels. Rao et al. (2015c) treated alcohol-preferring rats with CTX (100 mg/kg) for 2 or 5 days after a 5 -week period of voluntary drinking and found that although CTX reduced drinking at both times, GLT1 expression was only increased significantly at the 5 -day time point. In addition, Stennett et al. (2017) showed that CTX (200 mg/kg for 2 or 5 days) decreases alcohol consumption without changing GLT1 expression in the NAc. The morphine CPP and the development of locomotor sensitization are reduced by CLV (Schroeder et al., 2014) without evidence of altered GLT1 expression. CTX and CLV both block reinstatement of the methamphetamine CPP, but their effects on GLT1 expression differ substantially-CLV increased GLT1 expression (Althobaiti et al., 2019), whereas CTX did not (Abulseoud et al., 2012). Finally, and most importantly, Knackstedt and colleagues have shown conclusively that increased expression of GLT1 is not the mechanism by which antibiotics reduce cocaine reward (Logan et al., 2018; Bechard et al., 2019; Stennett et al., 2020). More recent studies have focused on CTX- and cocaine-induced alterations in the mGluR2 versus the GLT1 (Logan et al., 2020). Logan et al. (2020) demonstrated that CTX attenuates reinstatement of cocaine selfadministration, and a Glu2 receptor antagonist injected directly into the NAc blocks the effect of CTX.

4. Most studies highlighted in Tables 1-4 administered high doses of CTX ( $200 \mathrm{mg} / \mathrm{kg}$ is the most common dose) for 5-12 days prior to tests of reinstatement, a course of treatment known to significantly alter the composition of the gut microbiome in humans (Burdet et al., 2019) and animals alike (Luo et al., 2016; Connelly et al., 2017; Chakraborty et al., 2018; Luo et al., 2018; Holota et al., 2019; Miao et al., 2020). It is also interesting that the original report on CTXmediated neuroprotection used the same course of treatment in the G93A-SOD1 mouse model of amyotrophic lateral sclerosis (Rothstein et al., 2005), a mouse that is now known to have a leaky intestine and an impaired gut microbiome (Wu et al., 2015). Therefore, high-dose antibiotic treatment would impart an additional dysbiotic effect on a gut microbiome already substantially altered by drugs of abuse.

5. Antibiotic interference with the rewarding effects of drugs of abuse is partial. When the gut microbiome is given more consideration in studies of drug reward, it should be possible to use different and more-specific antibiotics as well as other well known and validated approaches to alter the gut microbiome to more completely prevent the rewarding effects of drugs of abuse. 
Angoa-Pérez and Kuhn

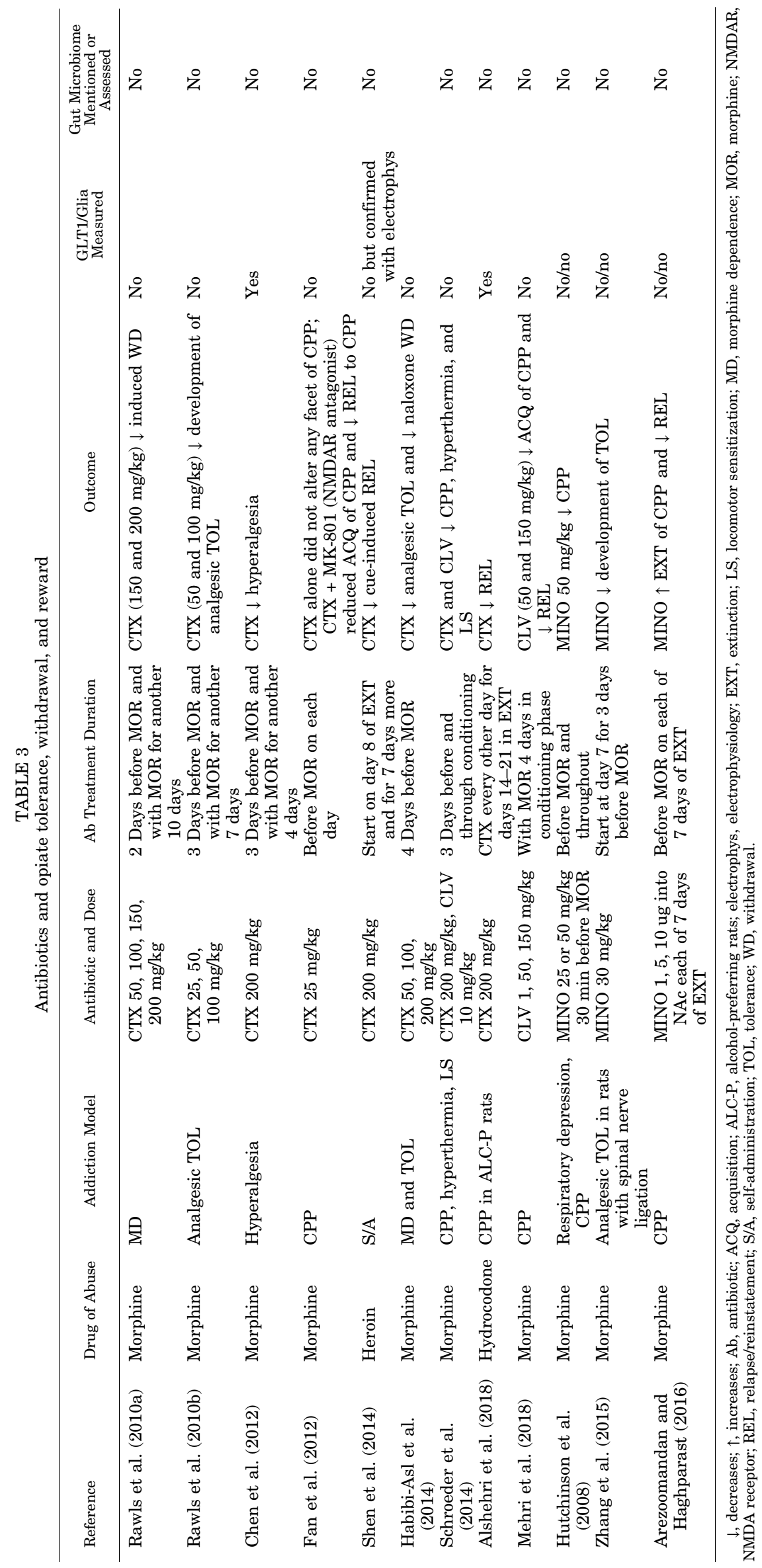


Drugs of Abuse and the Gut Microbiome

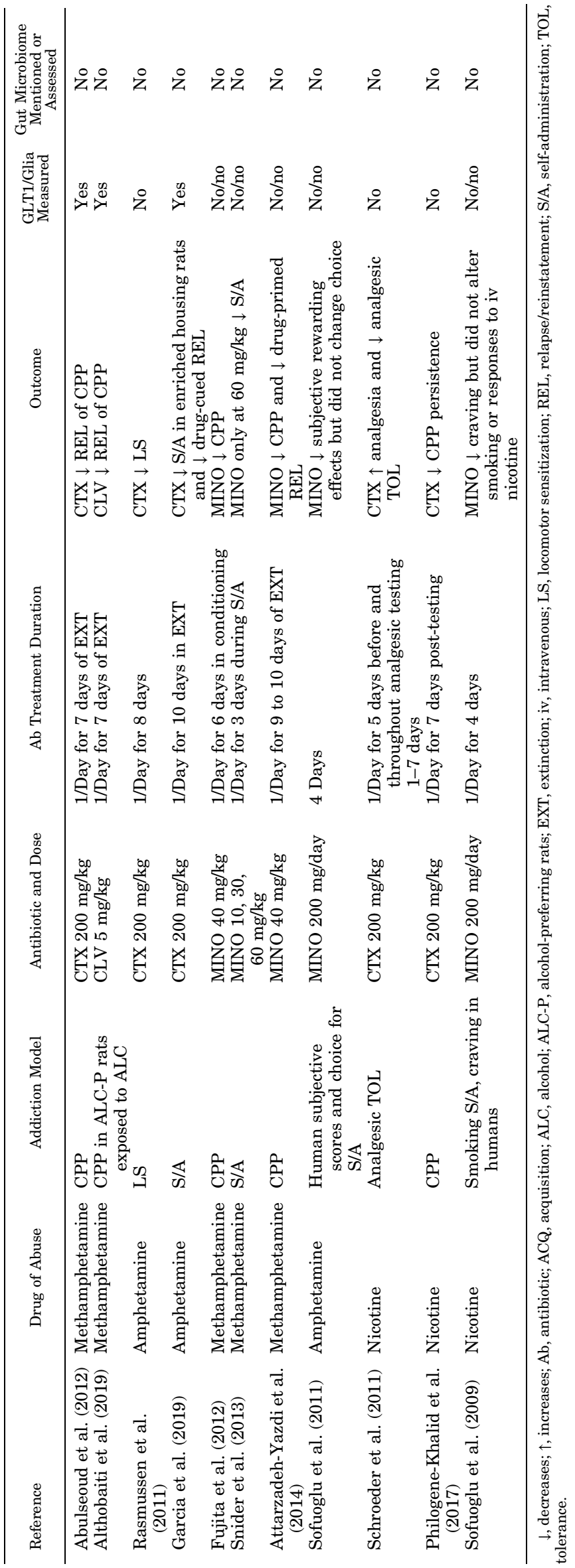


Taken together, abundant evidence exists implicating the gut microbiome in the mechanism by which antibiotics alter the rewarding effects of drugs of abuse. A role for the gut microbiome is rarely considered, but the disparities in outcomes described above justify a much more comprehensive analysis of how the gut microbiome can influence drug reward.

\section{Sodium Butyrate, Histone Deacetylase Enzymes, and Drugs of Abuse}

The intended use of $\mathrm{NaB}$ in modifying the dependencelike actions of drugs of abuse has been strictly as an inhibitor of histone deacetylase (HDAC) enzymes, which is an effect first demonstrated by Candido et al. (1978) in cultured cells. HDACs catalyze the removal of acetyl groups from lysine residues in histone proteins, an epigenetic modification that regulates chromatin structure and gene transcription (Seto and Yoshida, 2014). $\mathrm{NaB}$ is a weak inhibitor of class I (HDACs 1, 2, 3, and 8) and class IIa (HDACs 4, 5, 7, and 9) HDACs (Eckschlager et al., 2017). Broadly speaking, drugs of abuse can modulate gene transcription and expression via epigenetic mechanisms (Nestler, 2014; Cadet, 2016; Ajonijebu et al., 2017) such that chronic use leads to histone hypoacetylation via the action of HDACs. Therefore, HDAC inhibitors would block deacetylation, restoring gene transcription and expression to normal levels and preventing the transition to or reinstatement of drug use to the level of dependence. However, $\mathrm{NaB}$ has many pharmacological actions that go well beyond inhibition of HDACs as recently reviewed (Seto and Yoshida, 2014; Stilling et al., 2016; Dalile et al., 2019; Silva et al., 2020 ), and these can cloud interpretation of results when it is tested against the actions of drugs of abuse. Specifically, NaB can strengthen cocaine-associated contextual memory (Itzhak et al., 2013), trigger a stress response (Gagliano et al., 2014), and inhibit microglial activation (Huuskonen et al., 2004; Yamawaki et al., 2018), all of which could also modify the effects of drugs of abuse. In addition, the in vivo pharmacokinetics of $\mathrm{NaB}$ are such that it achieves very low bioavailability. Kim et al. (2013) found brain uptake of butyrate to be less than $0.006 \%$ after intravenous injections of radiolabeled butyrate in primates, leading Stilling et al. (2016) to conclude that it is unlikely that butyrate enters the brain in high enough concentrations to cause direct inhibition of HDACs.

With regard to the gut microbiome, butyric acid is a short-chain fatty acid (SCFA) that is synthesized during anaerobic microbial fermentation of polysaccharides, which cannot be digested by the host. Most butyrate-producing bacteria are found in phylum Firmicutes. Butyric acid can also be obtained from the diet (Stilling et al., 2016). From a pharmacological perspective, the sodium salt of butyric acid, $\mathrm{NaB}$, is the form used almost exclusively in studies aimed at modifying the actions of drugs of abuse. The administration of exogenous $\mathrm{NaB}$ modifies the gut microbiome (Zhou et al., 2017; Fang et al., 2019; Yu et al., 2019), so this could represent another mechanism by which it alters drug reward. Another emerging mechanism by which $\mathrm{NaB}$ could alter the actions of drugs of abuse via the gut-brain axis involves ghrelin signaling. Ghrelin is a 28-amino-acid peptide that is secreted by A-like-type cells of the stomach (Sakata and Sakai, 2010). Ghrelin signaling is mediated by the growth hormone secretagogue receptor 1a (GHSR1a), which is expressed in brain and modulates the appetite-inducing effects of ghrelin (Sakata and Sakai, 2010). It has been shown recently that butyrate and other SCFAs decrease ghrelin signaling by blocking GHSR1a (Torres-Fuentes et al., 2019). This is highly relevant to SUDs because ghrelin administration can increase alcohol intake and enhance preference for cocaine, whereas GHSR1a antagonists and GHSR1a gene knockouts show reduced voluntary intake of alcohol, stimulants, and nicotine, as reviewed recently (Panagopoulos and Ralevski, 2014; Zallar et al., 2017).

A. Sodium Butyrate and Cocaine. The literature on NaB-induced modification of cocaine actions is somewhat variable, and these studies are highlighted in Table 5. Most of these studies verified histone acetylation levels and/or changes in gene expression, but none included the gut microbiome in the interpretation of results. $\mathrm{NaB}$ decreases cocaine reward and increases cocaine extinction and reinstatement. $\mathrm{NaB}$ has been shown to increase cocaine self-administration (Sun et al., 2008), whereas phenylbutyrate, which is also used as an HDAC inhibitor, decreases self-administration and decreases motivation for cocaine (Romieu et al., 2008, 2011). In the CPP model of cocaine reward, $\mathrm{NaB}$ increases acquisition of a cocaine CPP (Raybuck et al., 2013) and decreases reinstatement of the extinguished CPP (Malvaez et al., 2010). Lower doses of $\mathrm{NaB}(300-600 \mathrm{mg} / \mathrm{kg})$ increase extinction of the cocaine CPP (Raybuck et al., 2013), whereas the higher dose of $1200 \mathrm{mg} / \mathrm{kg}$ can either increase (Malvaez et al., 2013) or decrease (Raybuck et al., 2013) extinction of the cocaine CPP. NaB does not modify the $D A D_{1}$ receptor $\left(D A D_{1} R\right)$ agonist-induced increase in a cocaine CPP (Schroeder et al., 2008). Finally, NaB increases the locomotor sensitization caused by cocaine (Sanchis-Segura et al., 2009) and cocaine plus a D1 agonist (Schroeder et al., 2008), suggesting enhancement of cocaine-induced reward. On the other hand, HDAC inhibitors other than $\mathrm{NaB}$ have fairly consistent effects on cocaine reward. For instance, the pan-HDAC inhibitor tricostatin A decreases cocaine self-administration (Romieu et al., 2008; Host et al., 2010; Romieu et al., 2011). The specific HDAC3 inhibitor RGFP966 increases extinction of the cocaine CPP (Malvaez et al., 2013) and increases extinction of cocaine self-administration and decreases its reinstatement (Hitchcock et al., 2019). The class I HDAC inhibitor 
MS-275 decreases cocaine locomotor sensitization (Kennedy et al., 2013). In contrast, the class II HDAC inhibitor MC1568 enhances cocaine self-administration (Griffin et al., 2017). These latter results add some substantiation to the conclusion that HDAC inhibition can alter cocaine actions. The roles played by epigenetics by cocaine have been reviewed (Kreek et al., 2012; Cadet, 2016).

B. Sodium Butyrate and Alcohol. A small number of studies have investigated the effects of $\mathrm{NaB}$ on alcohol drinking and reward, and these are highlighted in Table 5. The effects of $\mathrm{NaB}$ on histone acetylation levels and/or alterations in gene expression were verified in all. The gut microbiome was not considered in the interpretation of the data of any. It can be seen in Table 5 that $\mathrm{NaB}$ can either increase (Sanchis-Segura et al., 2009) or decrease (Legastelois et al., 2013) alcohol-induced locomotor sensitization. $\mathrm{NaB}$ increases acquisition of an alcohol CPP (Xu et al., 2012) but decreases alcohol drinking in dependent rats and prevents escalation to excessive drinking (Simon-O'Brien et al., 2015). The HDAC class I-specific inhibitor MS-275 reduces alcohol self-administration and decreases relapse (Jeanblanc et al., 2015). Valproic acid, a short branched-chain fatty acid derived from the SCFA valeric acid and an inhibitor of class I and IIA HDACs, lowers preference for alcohol and reduces consumption in the two-bottle choice paradigm, and it blocks formation of an alcohol CPP (Al Ameri et al., 2014). For the most part, the studies of $\mathrm{NaB}$ and alcohol are inconsistent, as is the case for cocaine, showing increases or decreases in alcohol dependence and reward. Nevertheless, all studies in Table 5 attributed the effects of $\mathrm{NaB}$ on alcohol reward to decreases in HDAC activity and/or epigenetic alterations. The role of HDAC inhibition and epigenetic alterations in alcohol reward and drinking has been reviewed (Palmisano and Pandey, 2017; Pandey et al., 2017; Ponomarev et al., 2017).

C. Sodium Butyrate and Opiates. The studies investigating NaB-opiate interactions are also highlighted in Table 5. The majority of these studies confirmed NaB-induced alterations in histone acetylation and/or gene expression, and none included discussion of the gut microbiome in the interpretation of results. Using the CPP model of drug reward, it has been shown that $\mathrm{NaB}$ increases the development of a morphine CPP (Sanchis-Segura et al., 2009) while increasing CPP extinction and reducing reinstatement (Wang et al., 2010). NaB has been shown to increase the development of locomotor sensitization (Sanchis-Segura et al., 2009), although it and valproic acid given separately decrease sensitization (Jing et al., 2011). Heroin self-administration is not altered by $\mathrm{NaB}$, and this HDAC inhibitor increases reinstatement of heroinprimed self-administration (Chen et al., 2016). Finally, the genetic deletion of the Per1 clock gene impairs the development of morphine-induced sensitization and the
CPP (Perreau-Lenz et al., 2017). Interestingly, these mice show significant increases in global levels of histone acetylation. Treatment of the Per1 knockout mice with $\mathrm{NaB}$ restores development of both morphine sensitization and CPP (Perreau-Lenz et al., 2017). In general, it is difficult to attribute NaB-induced alterations in the rewarding effects of opiates to HDAC inhibition because $\mathrm{NaB}$ can increase or decrease dependence-like behavior. $\mathrm{NaB}$ has no effect on opiate self-administration but can increase primed reinstatement of morphine self-administration, implying that HDAC inhibition increases seeking behavior for opiate reward. The role of HDAC inhibition and/or epigenetic alterations in opiate reward has been the subject of several review articles (Kreek et al., 2012; Browne et al., 2020).

D. Sodium Butyrate and Methamphetamine, Amphetamine, and Nicotine. $\mathrm{NaB}$ and other HDAC inhibitors have been tested with methamphetamine, amphetamine, and nicotine in a small number of studies, and these are highlighted in Table 5. NaB increases (Harkness et al., 2013), whereas valproic acid decreases (Coccurello et al., 2007), methamphetamineinduced locomotor sensitization. $\mathrm{NaB}$ has very complex effects on methamphetamine CPP in that it increases acquisition, increases extinction, and decreases reinstatement (Zhu et al., 2017). The effects of HDAC inhibitors on amphetamine-induced locomotor sensitization are equally confusing. The same investigators showed that $\mathrm{NaB}$ and valproic acid could decrease amphetamine sensitization (Kalda et al., 2007) and later reported that both HDACs increased it (Shen et al., 2008). $\mathrm{NaB}$ decreases reinstatement of nicotine self-administration only if given immediately after extinction but not if given a few hours later (Castino et al., 2015). Finally, phenylbutyrate decreases the nicotine-induced CPP (Pastor et al., 2011). The role of HDAC inhibition and/or epigenetic alterations in at least methamphetamine reward has been the subject of several review articles (Cadet and Jayanthi, 2013; Godino et al., 2015; Cadet, 2016).

E. Summary and Alternative Interpretations of Studies Examining Effects of Sodium Butyrate on the Rewarding Effects of Drugs of Abuse. Studies investigating the effects of $\mathrm{NaB}$ on the rewarding effects of drugs of abuse (see Table 5) attributed the outcomes to NaB-induced alterations in histone acetylation, chromatin remodeling, or epigenetic alterations. However, the outcomes of the studies in this section, as seen above for antibiotics, leave open the possibility that the gut microbiome is involved in NaB-induced reward reduction for the following reasons:

1. Several factors related to the pharmacology of $\mathrm{NaB}$, including the nonselective actions of high dose $\mathrm{NaB}$, the conflicting effects of $\mathrm{NaB}$ and other HDAC inhibitors on drug reward 


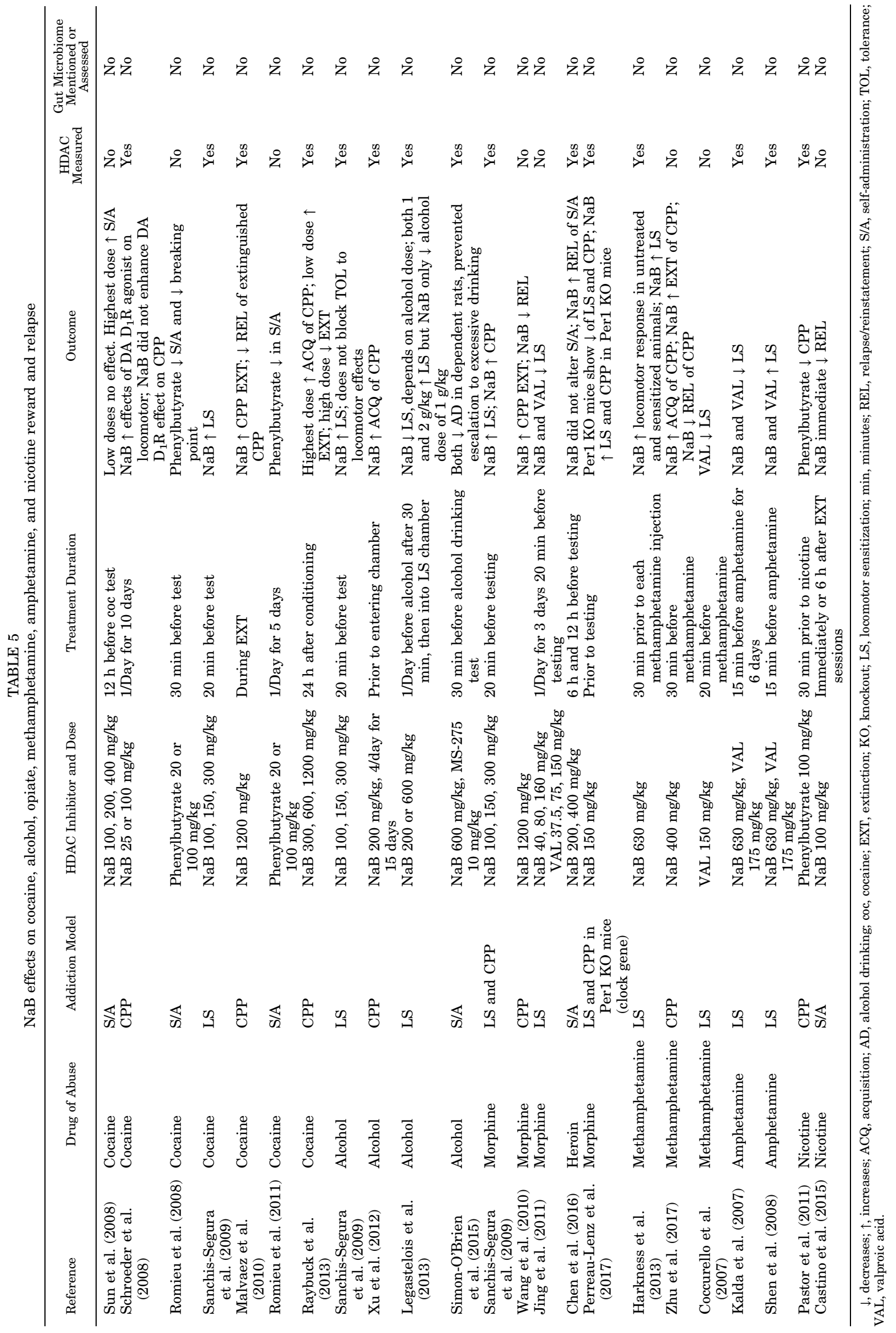


(some increase, some decrease) and the lack of correlation between levels of histone acetylation, and the effect of HDAC inhibitors on reward reduction, temper the conclusions on HDAC involvement.

2. Butyrate is produced endogenously by bacterial fermentation, and when given exogenously, it can cause alterations in the gut microbiome. It does not seem likely that the levels of butyrate in the circulation or in brain can achieve high enough concentrations to inhibit HDACs in the CNS even after dietary manipulations designed to do so (Stilling et al., 2016).

3. The ability of $\mathrm{NaB}$ to block the ghrelin receptor may be the primary mechanism by which it reduces cocaine reward, invoking a role for the gut-brain axis.

For these reasons and others discussed above, it is difficult to conclude that $\mathrm{NaB}$ is changing the dependence-like behaviors of drugs of abuse solely by inhibition of HDACs. These drugs of abuse have varying effects of their own on histone acetylation, and in some cases, they increase the levels of histone acetylation much like an HDAC inhibitor (see, for example, Harkness et al., 2013). Additional research on how HDAC inhibitors modify the dependence-like effects of the drugs of abuse should focus on endogenous microbial butyrate production and their interactions with the gut-brain axis.

\section{High-Fat Diet}

HFDs are most frequently used in combination with drugs of abuse because of the shared neuronal substrates activated by both the DA reward systems in the VTA-NAc axis and in the substantia nigradorsal striatum axis. These systems are thought to mediate motivation-reinforcement learning and action selection-goal-directed behavior, respectively (Volkow et al., 2017). Many drugs of abuse also interact directly or indirectly with the DA transporter (DAT) to increase the synaptic levels of DA via blocking uptake and/or causing release from presynaptic neurons via reverse transport through the DAT (Baladi et al., 2012a). Compulsive food intake and obesity, such as compulsive drug taking, are significant health problems in the USA. Therefore, a diet rich in fat and sugar could modulate sensitivity to the dependence-like effects of drugs of abuse, most likely by activating the central DA reward systems. HFD-drug interactions generally expose subjects to diets rich in fat and/or sucrose ad libitum or on a restricted access-binge schedule. Thereafter, subjects are tested for dependence-like effects of a drug to determine whether the diet modifies drugrelated behavior. Other variables of importance in these studies include sex and subject age (e.g., adolescence, adult, via maternal consumption) at the time of exposure to an experimental diet. In addition to activation of central DA reward pathways, diet and especially an HFD are well known to cause significant alterations in the gut microbiome (Spor et al., 2011; Goodrich et al., 2014; Xiao et al., 2015; Kim et al., 2017; Singh et al., 2017; Ericsson et al., 2018; Hills et al., 2019; Wu et al., 2019; Ezra-Nevo et al., 2020; Wilson et al., 2020), which can in turn alter microbial metabolic profiles that can reverberate throughout the body and into the CNS.

A. High-Fat Diet and Cocaine. Studies investigating the effects of HFD on the actions of cocaine have uncovered a number of interesting complexities, and these publications are highlighted in Table 6. Perhaps the first study to test the effects of an HFD on cocaine was published by Wellman et al. (2007), who reported that acquisition of self-administration was impaired in adult male rats. Morales et al. (2012) found that an HFD decreased the cocaine CPP. These early papers seem to be the exception, however, because most ensuing publications report that an HFD increases cocaine dependence-like behavior. For instance, Puhl et al. (2011) found that a history of restricted or binge-like consumption of an HFD enhances cocaine seeking and self-administration in adult male rats. Exposure of male rats to an HFD-binge intake during adolescence increases the cocaine CPP and self-administration in adulthood (Blanco-Gandía et al., 2017, 2018). These investigators also noted that adolescent rats housed in groups of three to four showed increased sensitivity to the development of a CPP to a subthreshold dose of cocaine, whereas singly housed rats fed standard chow were more sensitive to subthreshold doses of cocaine when tested in adulthood (Blanco-Gandía et al., 2018). To address the question of whether an HFD alters cocaine intake by increasing its rewarding properties or by decreasing its aversive properties, Clasen et al. (2020c) fed an HFD ad libitum to rats from adolescence into adulthood and then tested subjects for development of a CPP and a conditioned place aversion. These investigators reported that long-term exposure to the HFD altered neither the rewarding nor the aversive properties of cocaine (Clasen et al., 2020c). In a follow-up set of experiments, these same investigators reported that ad libitum feeding of an HFD from adolescence into adulthood significantly increased cocaine self-administration (Clasen et al., 2020b). A few studies have exposed pregnant rodents to HFD and then tested the offspring for their responsiveness to cocaine. The results from these studies are not in agreement, with one showing that maternal overnutrition did not alter locomotor responsiveness to cocaine in offspring (Sasaki et al., 2018), whereas a second study found that this treatment resulted in a greater CPP to cocaine in offspring (Peleg-Raibstein et al., 2016). Following the hypothesis that obesityprone and -resistant rats may have differential sensitivity to natural rewards that could extend to drug 
rewards, Thanos et al. (2010) tested obesity-resistant S5B and obesity-prone OM rats for development of a cocaine CPP. These investigators found that obesityprone OM rats did not show a significant cocaine CPP, whereas the obesity-resistant rats did (Thanos et al., 2010). On the other hand, Townsend et al. (2015) tested obese and lean Zucker rats for cocaine self-administration and found that the two groups did not differ in cocaine intake in a behavioral economic demand procedure. Both groups concluded that the results did not support a theory of common vulnerability for food and nonfood reinforcers despite the overlap in CNS reward pathways mediating each (Thanos et al., 2010; Townsend et al., 2015).

An extensive series of studies by France and colleagues has uncovered numerous interesting results with regard to the influence of sex, age of exposure to a fat-rich diet, and the method of exposure to HFD (restricted vs. ad libitum) on locomotor sensitivity to cocaine. These investigators reported initially that an HFD increased cocaine sensitivity in female rats with both free (Baladi et al., 2012b; Serafine et al., 2015, 2016) and restricted access to the diet (Baladi et al., 2012b). Free but not restricted access to an HFD for adult females also increased sensitivity to cocaine (Baladi et al., 2012b). In another study, Serafine et al. (2014) found that although adult female rats fed an HFD with either free or restricted access showed increased locomotor sensitization to cocaine, the effect of the HFD was not significant. When adolescent female rats were given free access to an HFD paired with either sucrose or saccharin in the drinking water, the development of cocaine locomotor sensitization was enhanced by the diet but not by sucrose or saccharin (Serafine et al., 2015). In contrast with an earlier study (Baladi et al., 2012b), this report found that restricted access to the HFD did not alter the development of locomotor sensitization in adolescent female rats (Serafine et al., 2015). Finally, adult male and female mice given free access to an HFD develop increased sensitization to the locomotor effects of acute cocaine (Collins et al., 2015). With repeated cocaine administration, adult female mice develop locomotor sensitization more rapidly when consuming sucrose, and this effect is not enhanced by an HFD (Collins et al., 2015).

B. High-Fat Diet and Alcohol. A small number of studies have examined the effects of HFD on alcohol drinking, and these studies are highlighted in Table 6 . Offspring from dams exposed to an HFD throughout pregnancy and lactation showed increased alcohol drinking in adulthood (Peleg-Raibstein et al., 2016). Adult rats given access to an HFD on an intermittent schedule significantly decreased their alcohol drinking (Sirohi et al., 2017; Villavasso et al., 2019). Coker et al. (2020) carried out an extensive analysis of the impact of HFD access schedules on alcohol drinking, and the results were very interesting. Mice given unlimited access to an HFD showed a significant decrease in drinking, whereas limited access to HFD (3 days/week) did not change alcohol drinking by comparison with controls, and intermittent access (a 24-hour session per week) led to increased alcohol drinking (Coker et al., 2020). It is clear that the discrepancies in the results of these studies may well result from the specific schedule of access to HFD. However, intermittent exposure to an HFD for 6 to 7 weeks can either decrease (Sirohi et al., 2017) or increase (Coker et al., 2020) alcohol drinking, so it appears that additional variables are operational. Data from the studies discussed above supported the conclusion that the observed outcomes were attributed to alterations in neurotransmitter neurochemistry (Peleg-Raibstein et al., 2016; Villavasso et al., 2019), decreased anxiety and elevated ghrelin (Sirohi et al., 2017), and the development of insulin insensitivity and glucose intolerance (Coker et al., 2020).

C. High-Fat Diet and Opiates. Few studies have determined the effects of an HFD on opiate reward, focusing instead on the larger issue of opioid modulation of food intake [see Taha (2010), Bodnar (2019) for reviews]. It has been reported that HFD-induced obesity increases morphine seeking and consumption in rats after bariatric surgery to lower their body weights, but the HFD had no effect on morphine reward in sham controls (Biegler et al., 2016). Rats fed a Western diet (high in palm oil and esterified fats) showed increased morphine reinstatement of an extinguished CPP, whereas rats fed a Mediterranean diet (low in fat) did not show relapse (Milanesi et al., 2019). The latter authors attributed the dietary effects on reinstatement of the morphine CPP to increases in DAT and DA $\mathrm{D}_{2}$ receptor $\left(\mathrm{DA} \mathrm{D}_{2} \mathrm{R}\right)$ levels in the NAc (Milanesi et al., 2019). These studies are included in Table 6.

D. High-Fat Diet and Methamphetamine, Amphetamine, and Nicotine. The effects of an HFD on methamphetamine, amphetamine, and nicotine reward have scarcely been investigated, and the publications that have done so are highlighted in Table 6 . It can be seen that an HFD increases the development of locomotor sensitization to methamphetamine (McGuire et al., 2011). With regard to amphetamine, an HFD decreases drinking (Kanarek et al., 1996) but increases the development of locomotor sensitization in the offspring of dams exposed to an HFD throughout pregnancy and lactation (Peleg-Raibstein et al., 2016). An HFD also decreases the amphetamine CPP (Davis et al., 2008). Mice fed an HFD do not develop a nicotine-induced CPP (Blendy et al., 2005), but after maternal overnutrition, offspring show increased self-administration of nicotine and decreased drug-primed reinstatement (Morganstern et al., 2013). It is clear from these studies that an HFD does not have a unitary effect on the rewarding properties of methamphetamine, amphetamine, or nicotine. 


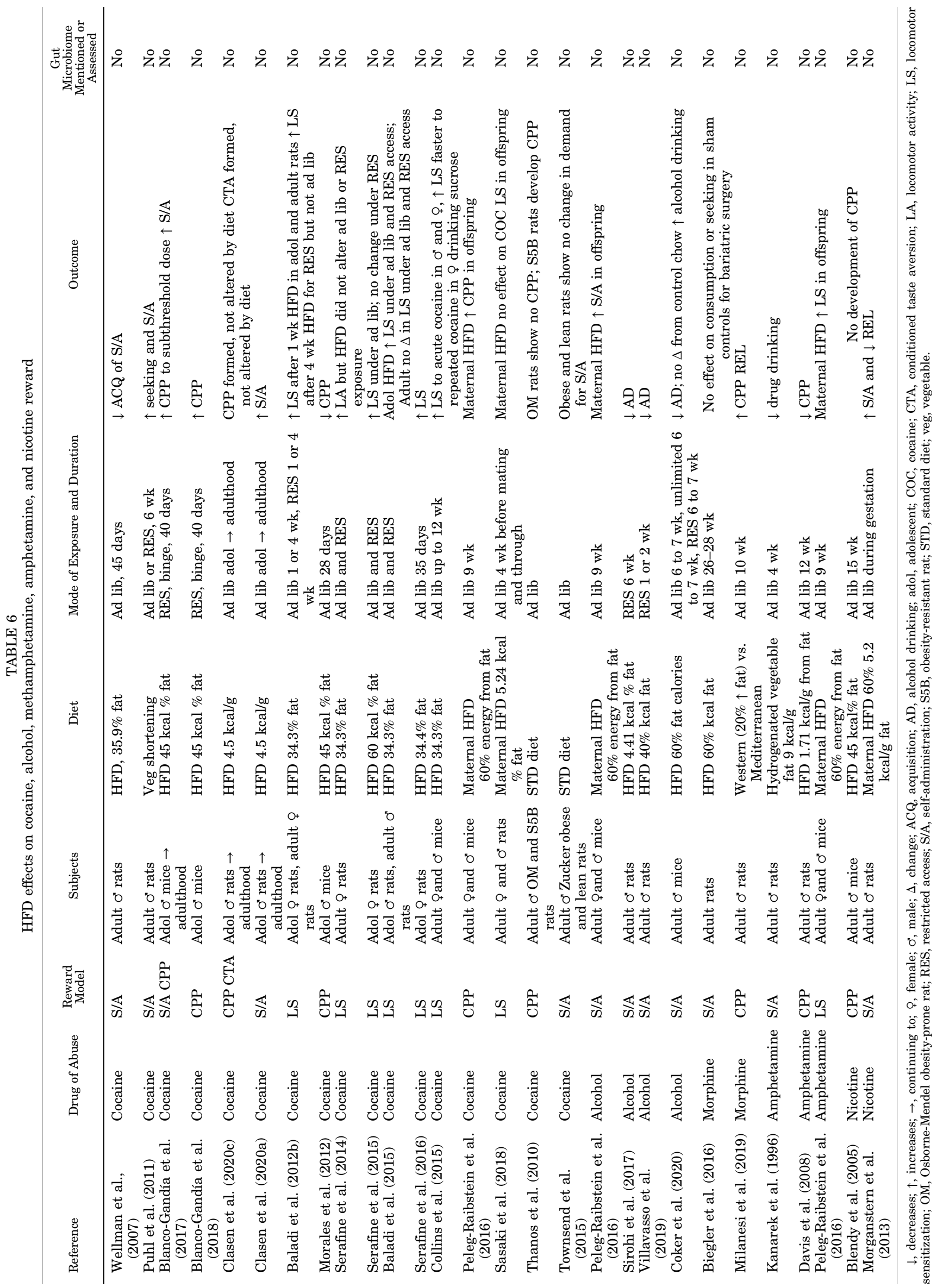


Most investigators attribute dietary effects on the rewarding properties of these drugs to overlapping reward pathways shared by overeating and drugs of abuse or to the anorectic effects of the amphetamines.

E. Summary and Alternative Interpretations of Studies Examining Effects of High-Fat Diet on the Rewarding Effects of Drugs of Abuse. Interpretation of the results of studies examining how an HFD changes sensitivity to cocaine within the construct of activation of overlapping DA reward pathways by fat and cocaine is complex. In general, it appears that an HFD increases sensitivity to the cocaine reward, but the results must be tempered because of some variability in outcomes. Interpretation is made more complex by the roles played by sex, age of subject when exposed to an HFD, the duration of exposure to the HFD, and animal housing conditions. Studies using self-administration and CPP agree that longer-term exposure of adolescent or adult male rodents to an HFD increases cocaine self-administration and development of a CPP. The fact that exposure to an HFD in adolescence, a time of enhanced vulnerability, extends heightened sensitivity to cocaine into adulthood is interesting and significant. Results from studies using obese versus lean animals fed standard diets and those that used cocaine-induced locomotor sensitization as the behavioral model show less agreement. Some of the more perplexing outcomes relate to the observation that an HFD enhances the locomotor-stimulating effects of cocaine in adolescent male rats but, against predictions, decreases striatal DA clearance, which led Baladi et al. (2015) to rule out the DAT as a mediator of the observed effects. Fish oil, which was used because of its documented ability to counter the inflammatory effects of HFDs, was found to prevent HFD-induced enhancement of locomotor sensitivity of adolescent females to cocaine, but its effects could not be linked to reductions in inflammatory cytokine markers (Serafine et al., 2016). The differential sensitivity of males and females to the locomotor-sensitizing effects of cocaine is also difficult to reconcile within the construct of the DA reward system (see Baladi et al., 2012a for review). Lastly, the finding that obesity-prone OM rats did not develop a cocaine CPP ran counter to expectations (Thanos et al., 2010). In this same study, the ability of the $\mathrm{DA} \mathrm{D}_{2} \mathrm{R}$ antagonist bromocriptine to reduce the cocaine CPP in obesity-resistant S5B rats led the authors to conclude that the $\mathrm{DA} \mathrm{D}_{2} \mathrm{R}$ played a partial regulatory role in the resistant rats. However, this effect was confounded somewhat by the observation that bromocriptine significantly reduced time spent in the cocainepaired chamber in the obesity-prone OM rats even though these subjects did not form a cocaine CPP (Thanos et al., 2010). For more extended discussions of how diet, food bingeing, and the DA reward system can interact to alter the rewarding properties of various drugs of abuse, the interested reader is referred to the following selected reviews: Bello and Hajnal (2010), Baladi et al. (2012a), Billing and Ersche (2015), de
Macedo et al. (2016), Blanco-Gandía and RodríguezArias (2017), and Volkow et al. (2017).

None of the publications discussed above include consideration of the gut microbiome in the interpretation of the results on drug-HFD interactions. However, it is clear that many of the variables that influence how an HFD can modulate the rewarding effects of drugs of abuse are closely linked to the gut microbiome, and for the reasons listed below, the gut microbiome cannot be ruled out:

1. An HFD causes extensive alterations in the composition and structure of the gut microbiome, so animals fed an HFD are metabolically quite different from animals fed standard laboratory chow. The administration of cocaine, alcohol, or amphetamines (which also alter the gut microbiome composition) on these differing backgrounds could have effects that are influenced as much by the dysbiotic microbiome as by alterations of central DA reward pathways.

2. Different housing conditions influence how an HFD modulates cocaine sensitization, but grouped versus individual housing has a significant impact on the gut microbiome as well (Spor et al., 2011; Xiao et al., 2015; Ericsson et al., 2018; Hylander and Repasky, 2019; Ringel-Scaia et al., 2019; Robertson et al., 2019).

3. Male-female differences influence the development of cocaine-induced locomotor sensitization, and they exert strong influence on the gut microbiome (Gomez et al., 2012; Markle et al., 2013; Xiao et al., 2015; Jašarević et al., 2016; Davis et al., 2017; Beale et al., 2019). Of particular relevance is the finding that highfat and high-sucrose diets differentially affect the gut microbiome of males and females (Daly et al., 2020).

4. Maternal obesity may influence cocaine reward in offspring, but it certainly exerts a powerful influence on the gut microbiome of offspring that persists into young adulthood (Buffington et al., 2016; Guo et al., 2018; Zhou and Xiao, 2018).

5 . The differing responses of at least the lean and obese Zucker rats to cocaine could be influenced by the vastly differing gut microbiomes in these rats (Hakkak et al., 2017).

\section{Summary, Conclusions, and Perspectives}

Over the past 10-15 years, a large number of studies have investigated the effects of antibiotics, $\mathrm{NaB}$, and an HFD on the rewarding effects of many drugs of abuse, and the greatest amount of focus has been on cocaine and alcohol. $\beta$-Lactam antibiotics were used in these studies for their ability to increase the levels of the GLT1 in the NAc. It now turns out that there is no 
relationship between the levels of expression of the GLT1 after treatment with $\beta$-lactam antibiotics and alterations in drug reward. In addition, the results of these studies also reveal significant variability with drug reward being increased, decreased, or not changed by antibiotics. Some of the variations seen in the highlighted studies can be linked directly to alterations in the gut microbiome. First, most drugs of abuse are now known to cause significant alterations in the composition of the gut microbiome. Second, all antibiotics used to alter drug reward are known to cause significant changes in the gut microbial communities as well. Third, any pairing of a particular drug of abuse (e.g., cocaine) with a particular antibiotic (e.g., CTX) will alter the gut microbiome in a manner that is specific for each drug in the pairing (see Ianiro et al., 2016 for examples of antibiotic specificity). Despite the overwhelmingly clear effects of antibiotics on the gut microbiome, all studies so far have focused on central mechanisms by which antibiotics alter the rewarding effects of drugs of abuse (e.g., mGluR2/3 vs. GLT1 Logan et al., 2020). In the absence of a relationship between the levels of GLT1 and alterations in drug reward by antibiotics, the knockdown of the gut microbiome by antibiotics remains an obvious, potential mechanism by which drug reward is altered, but unfortunately, the gut microbiome has not entered into the conceptualization of how antibiotics alter drug reward. Many of the highlighted studies even use the term " $\beta$-lactam antibiotic" in the title of published papers without any consideration that the effects of these antibiotics on drug reward could be occurring outside of the CNS.

A number of studies used $\mathrm{NaB}$ to alter drug reward, focusing on the ability of this compound to inhibit histone deacetylase enzymes. The outcomes of these studies are similar to those using antibiotics in that high doses of $\mathrm{NaB}$ can increase, decrease, or have no effect on drug reward. $\mathrm{NaB}$ is a short-chain fatty acid and a fermentation product of the gut microbiome that can also alter the structure and composition of the gut microbiome when given exogenously. Despite being given in very large doses (e.g., $1200 \mathrm{mg} / \mathrm{kg}$ ), $\mathrm{NaB}$ is a weak inhibitor of HDACs because of the limited bioavailability it achieves in vivo. In vitro studies have established that $\mathrm{NaB}$ is a broad-spectrum HDAC inhibitor that exerts actions on class I (HDACs $1,2,3$, and 8) and class IIa (HDACs 4, 5, 7, and 9) HDACs, so it is difficult to link drug actions to any specific enzyme form. It is likely the case that drug reward is mediated in part by epigenetic alterations (Nestler, 2014; Cadet, 2016; Ajonijebu et al., 2017), but it should be remembered that $\mathrm{NaB}$ and other SCFAs can cause epigenetic changes in the gut microbiome as well, and communication between the microbiome and host is mediated in part via epigenetic mechanisms (for reviews see Hullar and $\mathrm{Fu}$, 2014; Alam et al., 2017; Aleksandrova et al., 2017;
McKenzie et al., 2017; Kim and Jazwinski, 2018). Finally, the ability of $\mathrm{NaB}$ and other SCFAs to influence drug reward by interfering with ghrelin signaling represents another influential, peripherally based mechanism.

Feeding animals an HFD has generally been undertaken to study how overlapping food and drug reward mechanisms interact to modify drug reward. HFDs have varying effects on drug reward and can increase, decrease, or have little influence depending on the drug, the fat content of the diet, and the duration of the nutritional modification. Alcohol is unique among drugs of abuse in that it is nutritive and its interactions with CNS reward circuits and the gut microbiome differ from those of non-nutritive drugs of abuse (Alhadeff et al., 2019). On the other hand, diet is one of the most important determinants of the structure and composition of the gut microbiome. Both overnutrition (Spor et al., 2011; Goodrich et al., 2014; Xiao et al., 2015; Singh et al., 2017; Kim et al., 2017; Ericsson et al., 2018; Hills et al., 2019; Wu et al., 2019; Ezra-Nevo et al., 2020; Wilson et al., 2020) and undernutrition (Sonnenburg and Sonnenburg, 2014; Sonnenburg et al., 2016) cause extensive alterations in the gut microbiome. As is the case with studies of antibiotics and drugs of abuse, the combination of drug-induced dysbiosis with dietaryinduced dysbiosis will have effects on the gut microbiome that are specific to each pairing of a drug of abuse with an altered diet and that are different from either treatment alone. Adding to this complexity is the fact that selected drugs of abuse have GI effects (e.g., opiate constipation, cocaine ischemia) that can influence the gut microbiome in a manner that is different from drugs of abuse that do not have deleterious effects on GI function. With the foregoing discussion in mind, it is plausible to conclude that a role for the gut microbiome in SUDs cannot be ruled out and should be given additional attention going forward.

A large number of factors are thought to contribute to the variation in outcomes of studies of drugs of abuse and how antibiotics, $\mathrm{NaB}$, and HFDs interact to modify their rewarding properties. These include sex, prenatal exposure to drugs and modifiers, ad libitum versus binge feeding of altered diets, and the age of experimental subjects, to list a few. As more is learned about how the gut microbiome influences host health and well-being, it has become clear that these variables can have significant effects on the composition of the gut microbiome. In turn, these variables can contribute to the variability and irreproducibility seen in many animal models of disease (Franklin and Ericsson, 2017). Factors that may seem trivial are now known to disrupt the gut microbiome in rodents. Xiao et al. (2015) investigated some of those factors that have broad effects on the design and outcomes of experiments with mice and observed five major ones: mouse provider, housing laboratory/room, diet, sex, and mouse strain. The impact of these factors has been affirmed in other 
studies (Spor et al., 2011; Goodrich et al., 2014; Franklin and Ericsson, 2017; Ericsson et al., 2018). For example, regarding mouse vendors, C57BL/6 mice from Jackson Laboratory or Taconic Farms have significantly distinct microbiomes (Robertson et al., 2019). Other influential factors include drinking water, the birth/nursing dam, type of caging (e.g., static, ventilated), bedding, housing (e.g., single, grouped), fasting, and the maternal/cage effect (Spor et al., 2011; Goodrich et al., 2014; Franklin and Ericsson, 2017; Kim et al., 2017; Ericsson et al., 2018). With these factors in mind, it is easy to imagine that any one of them or several in combination can introduce unanticipated influences into an experiment, particularly when considering that drugs of abuse alter the gut microbiome.

Many other mechanisms exist by which the gut microbiome could modify the rewarding actions of drugs of abuse. A complete discussion of these mechanisms is well beyond the scope of this review, but a few examples are highly relevant and deserve mention. First, a very large number of marketed, nonantibiotic drugs are now known to have extensive impact on gut bacteria, and CNS-active drugs are overrepresented among all tested drugs for their ability to inhibit growth of selected bacterial strains (Maier et al., 2018). With few accepted medical uses, drugs of abuse have not been tested extensively for their bacteriostatic or bactericidal effects, but it is known that at least cocaine possesses significant antimicrobial activity (Johnson et al., 2008). Second, the gut microbiome has both direct and indirect effects on drug and xenobiotic metabolism (Wilson and Nicholson, 2017; Clarke et al., 2019; Zimmermann et al., 2019). For instance, the gut microbiome can carry out reductive metabolism and other biotransformations, including demethylation, deamination, dihydroxylation, decarboxylation, and oxidation (Wilson and Nicholson, 2017). Demethylation of methamphetamine by intestinal bacteria (Caldwell and Hawksworth, 1973) is but one example of how the metabolism, disposition, and bioavailability of a drug of abuse can be determined by gut bacteria. Third, alterations in tryptophan metabolism by the gut microbiome can modify the downstream kynurenine pathway (Kennedy et al., 2017), and it has been demonstrated that increases in kynurenic acid significantly reduce cue-induced reinstatement of both alcohol and cocaine-seeking behavior (Vengeliene et al., 2016). Increases in brain kynurenine levels also reduce alcohol consumption via its ability to inhibit DA release in the NAc (Giménez-Gómez et al., 2018). Fourth, and as mentioned above in paragraph IV, increases in butyrate production by the gut microbiome could interfere with ghrelin signaling, which is known to have profound effects on the rewarding effects of alcohol, stimulants, and nicotine (see Panagopoulos and Ralevski, 2014 and Zallar et al., 2017 for reviews). Last, the gut microbiome produces a large number of metabolites that agonize numerous G-protein-coupled receptors
(Cohen et al., 2017; Park et al., 2019), including various receptor subtypes for serotonin and DA (Chen et al., 2019; Colosimo et al., 2019). Therefore, alterations in gut production of these metabolites could interact with the same receptors implicated in the rewarding effects of drugs of abuse, such as the mGluR2 for reinstatement of cocaine seeking after treatment with CTX (Logan et al., 2020).

Based on the studies highlighted in Tables 1-6, it is clear that the gut microbiome has received very little attention in the interpretation of results from studies testing antibiotic, $\mathrm{NaB}$, or HFD interactions with drugs of abuse. However, it is undeniable that $\beta$-lactam antibiotics and HFDs cause substantial disruptions of the gut microbiome. Drug-induced dysbiosis could also shift the makeup of the microbiome such that experimental animals differ from controls not only based on drug treatment but on the interaction of that particular drug with numerous other dysbiosis-causing factors. More direct and specific assessment of the role of the gut microbiome in SUDs could lead to a better understanding of the mechanisms underlying drug abuse and thereby suggest new therapies. Although it is still too early to consider them for the treatment of SUD-related complications, manipulations of the gut microbiome-brain axis through supplementation of nutritional dietary components, such as prebiotics (i.e., indigestible fiber), and probiotics (beneficial live microorganisms) (Liu et al., 2015), as well as fecal microbiota transplantation constitute available tools that could aid in the design of studies aiming to assess the potential role of the gut microbiome in SUDs. Accounting for the potential roles played by the gut microbiome in SUDs, especially when using animal models, would increase experimental rigor and reproducibility and reduce variability in outcomes.

\section{Authorship Contributions}

Participated in research design: Angoa-Pérez, Kuhn.

Performed data analysis: Angoa-Pérez, Kuhn.

Wrote or contributed to the writing of the manuscript: AngoaPérez, Kuhn.

\section{References}

Abulseoud OA, Camsari UM, Ruby CL, Kasasbeh A, Choi S, and Choi DS (2014) Attenuation of ethanol withdrawal by ceftriaxone-induced upregulation of glutamate transporter EAAT2. Neuropsychopharmacology 39:1674-1684.

Abulseoud OA, Miller JD, Wu J, Choi DS, and Holschneider DP (2012) Ceftriaxone upregulates the glutamate transporter in medial prefrontal cortex and blocks reinstatement of methamphetamine seeking in a condition place preference paradigm. Brain Res 1456:14-21.

Acharya C, Betrapally NS, Gillevet PM, Sterling RK, Akbarali H, White MB, Ganapathy D, Fagan A, Sikaroodi M, and Bajaj JS (2017) Chronic opioid use is associated with altered gut microbiota and predicts readmissions in patients with cirrhosis. Aliment Pharmacol Ther 45:319-331.

Agrawal RG, Hewetson A, George CM, Syapin PJ, and Bergeson SE (2011) Minocycline reduces ethanol drinking. Brain Behav Immun 25 (Suppl 1):S165-S169.

Ajonijebu DC, Abboussi O, Russell VA, Mabandla MV, and Daniels WMU (2017) Epigenetics: a link between addiction and social environment. Cell Mol Life Sci 74: 2735-2747.

Akbarali HI and Dewey WL (2017) The gut-brain interaction in opioid tolerance. Curr Opin Pharmacol 37:126-130.

Akbarali HI, Inkisar A, and Dewey WL (2014) Site and mechanism of morphine tolerance in the gastrointestinal tract. Neurogastroenterol Motil 26:1361-1367.

Al Ameri M, Al Mansouri S, Al Maamari A, and Bahi A (2014) The histone deacetylase (HDAC) inhibitor valproic acid reduces ethanol consumption and ethanolconditioned place preference in rats. Brain Res 1583:122-131. 
Alajaji M, Bowers MS, Knackstedt L, and Damaj MI (2013) Effects of the beta-lactam antibiotic ceftriaxone on nicotine withdrawal and nicotine-induced reinstatement of preference in mice. Psychopharmacology (Berl) 228:419-426.

Alam R, Abdolmaleky HM, and Zhou JR (2017) Microbiome, inflammation, epigenetic alterations, and mental diseases. Am J Med Genet B Neuropsychiatr Genet 174: $651-660$.

Aleksandrova K, Romero-Mosquera B, and Hernandez V (2017) Diet, gut microbiome and epigenetics: emerging links with inflammatory bowel diseases and prospects for management and prevention. Nutrients 9:1-13.

Al-Ghezi ZZ, Busbee PB, Alghetaa H, Nagarkatti PS, and Nagarkatti M (2019) Combination of cannabinoids, delta-9-tetrahydrocannabinol (THC) and cannabidiol (CBD), mitigates experimental autoimmune encephalomyelitis (EAE) by altering the gut microbiome. Brain Behav Immun 82:25-35.

Alhaddad H, Das SC, and Sari Y (2014) Effects of ceftriaxone on ethanol intake: a possible role for xCT and GLT-1 isoforms modulation of glutamate levels in P rats. Psychopharmacology (Berl) 231:4049-4057.

Alhadeff AL, Goldstein N, Park O, Klima ML, Vargas A, and Betley JN (2019) Natural and drug rewards engage distinct pathways that converge on coordinated hypothalamic and reward circuits. Neuron 103:891-908.e6.

Allais L, Kerckhof FM, Verschuere S, Bracke KR, De Smet R, Laukens D, Van den Abbeele P, De Vos M, Boon N, Brusselle GG, et al. (2016) Chronic cigarette smoke exposure induces microbial and inflammatory shifts and mucin changes in the murine gut. Environ Microbiol 18:1352-1363.

Alshehri FS, Hakami AY, Althobaiti YS, and Sari Y (2018) Effects of ceftriaxone on hydrocodone seeking behavior and glial glutamate transporters in $\mathrm{P}$ rats. Behav Brain Res 347:368-376.

Althobaiti YS, Alshehri FS, Hakami AY, Hammad AM, and Sari Y (2019) Effects of clavulanic acid treatment on reinstatement to methamphetamine, glial glutamate transporters, and mGluR 2/3 expression in $\mathrm{P}$ rats exposed to ethanol. $\mathrm{J} \mathrm{Mol} \mathrm{Neu}$ rosci 67:1-15.

Angoa-Pérez M, Zagorac B, Winters AD, Greenberg JM, Ahmad M, Theis KR, and Kuhn DM (2020) Differential effects of synthetic psychoactive cathinones and amphetamine stimulants on the gut microbiome in mice. PLoS One 15:e0227774.

Arezoomandan R and Haghparast A (2016) Administration of the glial cell modulator, minocycline, in the nucleus accumbens attenuated the maintenance and reinstatement of morphine-seeking behavior. Can J Physiol Pharmacol 94:257-264.

Attarzadeh-Yazdi G, Arezoomandan R, and Haghparast A (2014) Minocycline, an antibiotic with inhibitory effect on microglial activation, attenuates the maintenance and reinstatement of methamphetamine-seeking behavior in rat. Prog Neuropsychopharmacol Biol Psychiatry 53:142-148.

Avena NM, Bocarsly ME, Hoebel BG, and Gold MS (2011) Overlaps in the nosology of substance abuse and overeating: the translational implications of "food addiction". Curr Drug Abuse Rev 4:133-139.

Avena NM, Rada P, and Hoebel BG (2008) Evidence for sugar addiction: behavioral and neurochemical effects of intermittent, excessive sugar intake. Neurosci Biobehav Rev 32:20-39.

Avena NM, Rada P, and Hoebel BG (2009) Sugar and fat bingeing have notable differences in addictive-like behavior. J Nutr 139:623-628.

Baladi MG, Daws LC, and France CP (2012a) You are what you eat: influence of type and amount of food consumed on central dopamine systems and the behavioral effects of direct- and indirect-acting dopamine receptor agonists. Neuropharmacology 63:76-86.

Baladi MG, Horton RE, Owens WA, Daws LC, and France CP (2015) Eating high fat chow decreases dopamine clearance in adolescent and adult male rats but selectively enhances the locomotor stimulating effects of cocaine in adolescents. Int $J$ Neuropsychopharmacol 18:pyv024.

Baladi MG, Koek W, Aumann M, Velasco F, and France CP (2012b) Eating high fat chow enhances the locomotor-stimulating effects of cocaine in adolescent and adult female rats. Psychopharmacology (Berl) 222:447-457.

Banerjee S, Sindberg G, Wang F, Meng J, Sharma U, Zhang L, Dauer P, Chen C, Dalluge J, Johnson T, et al. (2016) Opioid-induced gut microbial disruption and bile dysregulation leads to gut barrier compromise and sustained systemic inflammation. Mucosal Immunol 9:1418-1428.

Barr JL, Rasmussen BA, Tallarida CS, Scholl JL, Forster GL, Unterwald EM, and Rawls SM (2015) Ceftriaxone attenuates acute cocaine-evoked dopaminergic neurotransmission in the nucleus accumbens of the rat. $\mathrm{Br} J$ Pharmacol $\mathbf{1 7 2}$ $5414-5424$

Barr T, Sureshchandra S, Ruegger P, Zhang J, Ma W, Borneman J, Grant K, and Messaoudi I (2018) Concurrent gut transcriptome and microbiota profiling following chronic ethanol consumption in nonhuman primates. Gut Microbes $\mathbf{9}$ 338-356

Beale AL, Kaye DM, and Marques FZ (2019) The role of the gut microbiome in sex differences in arterial pressure. Biol Sex Differ 10:22

Becattini S, Taur Y, and Pamer EG (2016) Antibiotic-induced changes in the intestinal microbiota and disease. Trends Mol Med 22:458-478.

Bechard AR, Hamor PU, Schwendt M, and Knackstedt LA (2018) The effects of ceftriaxone on cue-primed reinstatement of cocaine-seeking in male and female rats: estrous cycle effects on behavior and protein expression in the nucleus accumbens. Psychopharmacology (Berl) 235:837-848.

Bechard AR, Hamor PU, Wu L, Schwendt M, and Knackstedt LA (2019) The effects of clavulanic acid and amoxicillin on cue-primed reinstatement of cocaine seeking. Behav Neurosci 133:247-254.

Bechard AR and Knackstedt LA (2019) The effects of Pavlovian cue extinction and ceftriaxone on cocaine relapse after abstinence. Drug Alcohol Depend 197: $83-86$

Bell RL, Hauser SR, Liang T, Sari Y, Maldonado-Devincci A, and Rodd ZA (2017) Rat animal models for screening medications to treat alcohol use disorders. Neuropharmacology 122:201-243.

Bello NT and Hajnal A (2010) Dopamine and binge eating behaviors. Pharmacol Biochem Behav 97:25-33.
Bergeson SE, Nipper MA, Jensen J, Helms ML, and Finn DA (2016) Tigecycline reduces ethanol intake in dependent and nondependent male and female C57BL 6J mice. Alcohol Clin Exp Res 40:2491-2498.

Bertacco A, Dehner CA, Caturegli G, D’Amico F, Morotti R, Rodriguez MI, Mulligan DC, Kriegel MA, and Geibel JP (2017) Modulation of intestinal microbiome prevents intestinal ischemic injury. Front Physiol 8:1064.

Biegler JM, Freet CS, Horvath N, Rogers AM, and Hajnal A (2016) Increased intravenous morphine self-administration following Roux-en-Y gastric bypass in dietary obese rats. Brain Res Bull 123:47-52.

Billing L and Ersche KD (2015) Cocaine's appetite for fat and the consequences on body weight. Am J Drug Alcohol Abuse 41:115-118.

Bjørkhaug ST, Aanes H, Neupane SP, Bramness JG, Malvik S, Henriksen C, Skar V, Medhus AW, and Valeur J (2019) Characterization of gut microbiota composition and functions in patients with chronic alcohol overconsumption. Gut Microbes 10: $663-675$

Blanco-Gandía MC, Cantacorps L, Aracil-Fernández A, Montagud-Romero S, Aguilar MA, Manzanares J, Valverde O, Miñarro J, and Rodríguez-Arias M (2017) Effects of bingeing on fat during adolescence on the reinforcing effects of cocaine in adult male mice. Neuropharmacology 113:31-44.

Blanco-Gandía MC, Montagud-Romero S, Aguilar MA, Miñarro J, and RodríguezArias M (2018) Housing conditions modulate the reinforcing properties of cocaine in adolescent mice that binge on fat. Physiol Behav 183:18-26.

Blanco-Gandía MC and Rodríguez-Arias M (2017) Bingeing on fat increases cocaine reward. Oncotarget 8:16105-16106.

Blendy JA, Strasser A, Walters CL, Perkins KA, Patterson F, Berkowitz R, and Lerman C (2005) Reduced nicotine reward in obesity: cross-comparison in human and mouse. Psychopharmacology (Berl) 180:306-315.

Bluemel S, Wang L, Kuelbs C, Moncera K, Torralba M, Singh H, Fouts DE, and Schnabl B (2020) Intestinal and hepatic microbiota changes associated with chronic ethanol administration in mice. Gut Microbes 11:265-275.

Bodnar RJ (2019) Endogenous opioid modulation of food intake and body weight: implications for opioid influences upon motivation and addiction. Peptides 116: 42-62.

Browne CJ, Godino A, Salery M, and Nestler EJ (2020) Epigenetic mechanisms of opioid addiction. Biol Psychiatry 87:22-33.

Buffington SA, Di Prisco GV, Auchtung TA, Ajami NJ, Petrosino JF, and CostaMattioli M (2016) Microbial reconstitution reverses maternal diet-induced social and synaptic deficits in offspring. Cell 165:1762-1775.

Bull-Otterson L, Feng W, Kirpich I, Wang Y, Qin X, Liu Y, Gobejishvili L, Joshi-Barve S, Ayvaz T, Petrosino J, et al. (2013) Metagenomic analyses of alcohol induced pathogenic alterations in the intestinal microbiome and the effect of Lactobacillus rhamnosus GG treatment. PLoS One 8:e53028.

Burdet C, Grall N, Linard M, Bridier-Nahmias A, Benhayoun M, Bourabha K, Magnan M, Clermont O, d'Humières C, Tenaillon O, et al.; CEREMI Group (2019) Ceftriaxone and cefotaxime have similar effects on the intestinal microbiota in human volunteers treated by standard-dose regimens. Antimicrob Agents Chemother 63:1-12.

Cadet JL (2016) Epigenetics of stress, addiction, and resilience: therapeutic implications. Mol Neurobiol 53:545-560.

Cadet JL and Jayanthi S (2013) Epigenetics of methamphetamine-induced changes in glutamate function. Neuropsychopharmacology 38:248-249.

Caldwell J and Hawksworth GM (1973) The demethylation of methamphetamine by intestinal microflora. J Pharm Pharmacol 25:422-424.

Candido EP, Reeves R, and Davie JR (1978) Sodium butyrate inhibits histone deacetylation in cultured cells. Cell 14:105-113.

Carabotti M, Scirocco A, Maselli MA, and Severi C (2015) The gut-brain axis: interactions between enteric microbiota, central and enteric nervous systems. Ann Gastroenterol 28:203-209.

Castino MR, Cornish JL, and Clemens KJ (2015) Inhibition of histone deacetylases facilitates extinction and attenuates reinstatement of nicotine self-administration in rats. PLoS One 10:e124796.

Caton SJ, Nolan LJ, and Hetherington MM (2015) Alcohol, appetite and loss of restraint. Curr Obes Rep 4:99-105.

Chakraborty R, Lam V, Kommineni S, Stromich J, Hayward M, Kristich CJ, and Salzman $\mathrm{NH}$ (2018) Ceftriaxone administration disrupts intestinal homeostasis, mediating noninflammatory proliferation and dissemination of commensal enterococci. Infect Immun 86:e00674-e00718.

Chen H, Nwe PK, Yang Y, Rosen CE, Bielecka AA, Kuchroo M, Cline GW, Kruse AC, Ring AM, Crawford JM, et al. (2019) A forward chemical genetic screen reveals gut microbiota metabolites that modulate host physiology. Cell 177:1217-1231.e18.

Chen H, Uz T, and Manev H (2009) Minocycline affects cocaine sensitization in mice. Neurosci Lett 452:258-261.

Chen WS, Xu WJ, Zhu HQ, Gao L, Lai MJ, Zhang FQ, Zhou WH, and Liu HF (2016) Effects of histone deacetylase inhibitor sodium butyrate on heroin seeking behavior in the nucleus accumbens in rats. Brain Res 1652:151-157.

Chen Z, He Y, and Wang ZJ (2012) The beta-lactam antibiotic, ceftriaxone, inhibits the development of opioid-induced hyperalgesia in mice. Neurosci Lett 509:69-71.

Chi L, Mahbub R, Gao B, Bian X, Tu P, Ru H, and Lu K (2017) Nicotine alters the gut microbiome and metabolites of gut-brain interactions in a sex-specific manner. Chem Res Toxicol 30:2110-2119.

Chivero ET, Ahmad R, Thangaraj A, Periyasamy P, Kumar B, Kroeger E, Feng D, Guo ML, Roy S, Dhawan P, et al. (2019) Cocaine induces inflammatory gut milieu by compromising the mucosal barrier integrity and altering the gut microbiota colonization. Sci Rep 9:12187.

Clarke G, Sandhu KV, Griffin BT, Dinan TG, Cryan JF, and Hyland NP (2019) Gut reactions: breaking down xenobiotic-microbiome interactions. Pharmacol Rev $\mathbf{7 1}$ $198-224$.

Clasen MM, Riley AL, and Davidson TL (2020a) Hippocampal-dependent inhibitory learning and memory processes in the control of eating and drug taking. Curr Pharm Des 26:2334-2352. 
Clasen MM, Sanon TV, Hempel BJ, Nelson KH, Kearns DN, Davidson TL, and Riley AL (2020b) Ad-libitum high fat diet consumption during adolescence and adulthood impacts the intravenous self-administration of cocaine in male Sprague-Dawley rats. Exp Clin Psychopharmacol 28:32-43.

Clasen MM, Sanon TV, Kearns DN, Davidson TL, and Riley AL (2020c) Ad libitum high fat diet consumption during adolescence and adulthood fails to impact the affective properties of cocaine in male Sprague-Dawley rats. Exp Clin Psychopharmacol 28:438-448.

Cluny NL, Keenan CM, Reimer RA, Le Foll B, and Sharkey KA (2015) Prevention of diet-induced obesity effects on body weight and gut microbiota in mice treated chronically with $\Delta$ 9-tetrahydrocannabinol. PLoS One 10:e144270.

Coccurello R, Caprioli A, Ghirardi O, and Virmani A (2007) Valproate and acetyl-Lcarnitine prevent methamphetamine-induced behavioral sensitization in mice. Ann N Y Acad Sci 1122:260-275.

Cohen LJ, Esterhazy D, Kim SH, Lemetre C, Aguilar RR, Gordon EA, Pickard AJ, Cross JR, Emiliano AB, Han SM, et al. (2017) Commensal bacteria make GPCR ligands that mimic human signalling molecules. Nature 549:48-53.

Coker CR, Aguilar EA, Snyder AE, Bingaman SS, Graziane NM, Browning KN, Arnold AC, and Silberman Y (2020) Access schedules mediate the impact of high fat diet on ethanol intake and insulin and glucose function in mice. Alcohol $\mathbf{8 6}$ : $45-56$

Collins GT, Chen Y, Tschumi C, Rush EL, Mensah A, Koek W, and France CP (2015) Effects of consuming a diet high in fat and/or sugar on the locomotor effects of acute and repeated cocaine in male and female C57BL/6J mice. Exp Clin Psychopharmacol 23:228-237.

Colosimo DA, Kohn JA, Luo PM, Piscotta FJ, Han SM, Pickard AJ, Rao A, Cross JR, Cohen LJ, and Brady SF (2019) Mapping interactions of microbial metabolites with human g-protein-coupled receptors. Cell Host Microbe 26:273-282.e7.

Connelly S, Bristol JA, Hubert S, Subramanian P, Hasan NA, Colwell RR, and Kaleko M (2017) SYN-004 (ribaxamase), an oral beta-lactamase, mitigates antibiotic-mediated dysbiosis in a porcine gut microbiome model. J Appl Microbiol 123:66-79.

Cryan JF and O'Mahony SM (2011) The microbiome-gut-brain axis: from bowel to behavior. Neurogastroenterol Motil 23:187-192.

Cryan JF, O’Riordan KJ, Cowan CSM, Sandhu KV, Bastiaanssen TFS, Boehme M, Codagnone MG, Cussotto S, Fulling C, Golubeva AV, et al. (2019) The microbiotagut-brain axis. Physiol Rev 99:1877-2013.

Dalile B, Van Oudenhove L, Vervliet B, and Verbeke K (2019) The role of short-chain fatty acids in microbiota-gut-brain communication. Nat Rev Gastroenterol Hepatol 16:461-478.

Daly CM, Saxena J, Singh J, Bullard MR, Bondy EO, Saxena A, Buffalino RE, Melville MF, and Freeman LR (2020) Sex differences in response to a high fat, high sucrose diet in both the gut microbiome and hypothalamic astrocytes and microglia. Nutr Neurosci DOI: 10.1080/1028415X.2020.1752996 [published ahead of print].

Das SC, Yamamoto BK, Hristov AM, and Sari Y (2015) Ceftriaxone attenuates ethanol drinking and restores extracellular glutamate concentration through normalization of GLT-1 in nucleus accumbens of male alcohol-preferring rats. Neuropharmacology 97:67-74.

Davis DJ, Hecht PM, Jasarevic E, Beversdorf DQ, Will MJ, Fritsche K, and Gillespie CH (2017) Sex-specific effects of docosahexaenoic acid (DHA) on the microbiome and behavior of socially-isolated mice. Brain Behav Immun 59:38-48.

Davis JF, Tracy AL, Schurdak JD, Tschöp MH, Lipton JW, Clegg DJ, and Benoit SC (2008) Exposure to elevated levels of dietary fat attenuates psychostimulant reward and mesolimbic dopamine turnover in the rat. Behav Neurosci 122 $1257-1263$

de Araujo IE, Ferreira JG, Tellez LA, Ren X, and Yeckel CW (2012) The gut-brain dopamine axis: a regulatory system for caloric intake. Physiol Behav 106:394-399.

de Macedo IC, de Freitas JS, and da Silva Torres IL (2016) The influence of palatable diets in reward system activation: a mini review. Adv Pharmacol Sci 2016 7238679

Dimidi E, Christodoulides S, Scott SM, and Whelan K (2017) Mechanisms of action of probiotics and the gastrointestinal microbiota on gut motility and constipation. Adv Nutr 8:484-494.

Dinan TG and Cryan JF (2017) The microbiome-gut-brain axis in health and disease. Gastroenterol Clin North Am 46:77-89.

Dubinkina VB, Tyakht AV, Odintsova VY, Yarygin KS, Kovarsky BA, Pavlenko AV, Ischenko DS, Popenko AS, Alexeev DG, Taraskina AY, et al. (2017) Links of gut microbiota composition with alcohol dependence syndrome and alcoholic liver disease. Microbiome 5:141.

Eckschlager T, Plch J, Stiborova M, and Hrabeta J (2017) Histone deacetylase inhibitors as anticancer drugs. Int $J$ Mol Sci 18:1-25.

Engen PA, Green SJ, Voigt RM, Forsyth CB, and Keshavarzian A (2015) The gastrointestinal microbiome: alcohol effects on the composition of intestinal microbiota. Alcohol Res 37:223-236.

Ericsson AC, Gagliardi J, Bouhan D, Spollen WG, Givan SA, and Franklin CL (2018) The influence of caging, bedding, and diet on the composition of the microbiota in different regions of the mouse gut. Sci Rep 8:4065.

Ezra-Nevo G, Henriques SF, and Ribeiro C (2020) The diet-microbiome tango: how nutrients lead the gut brain axis. Curr Opin Neurobiol 62:122-132.

Falony G, Joossens M, Vieira-Silva S, Wang J, Darzi Y, Faust K, Kurilshikov A, Bonder MJ, Valles-Colomer M, Vandeputte D, et al. (2016) Population-level analysis of gut microbiome variation. Science 352:560-564.

Fan Y, Niu H, Rizak JD, Li L, Wang G, Xu L, Ren H, Lei H, and Yu H (2012) Combined action of MK- 801 and ceftriaxone impairs the acquisition and reinstatement of morphine-induced conditioned place preference, and delays morphine extinction in rats. Neurosci Bull 28:567-576.

Fan Y, Ya-E Z, Ji-Dong W, Yu-Fan L, Ying Z, Ya-Lun S, Meng-Yu M, and Rui-Ling Z (2018) Comparison of microbial diversity and composition in jejunum and colon of the alcohol-dependent rats. J Microbiol Biotechnol 28:1883-1895.
Fang W, Xue H, Chen X, Chen K, and Ling W (2019) Supplementation with sodium butyrate modulates the composition of the gut microbiota and ameliorates high-fat diet-induced obesity in mice. $J$ Nutr 149:747-754

Fernandes AB, Alves da Silva J, Almeida J, Cui G, Gerfen CR, Costa RM, and Oliveira-Maia AJ (2020) Postingestive modulation of food seeking depends on vagus-mediated dopamine neuron activity. Neuron 106:778-788.e6.

Ferreira JG, Tellez LA, Ren X, Yeckel CW, and de Araujo IE (2012) Regulation of fat intake in the absence of flavour signalling. J Physiol 590:953-972.

Ferrer M, Méndez-García C, Rojo D, Barbas C, and Moya A (2017) Antibiotic use and microbiome function. Biochem Pharmacol 134:114-126.

Finlay J, Miller L, and Poupard JA (2003) A review of the antimicrobial activity of clavulanate. J Antimicrob Chemother 52:18-23.

Fischer KD, Houston AC, and Rebec GV (2013) Role of the major glutamate transporter GLT1 in nucleus accumbens core versus shell in cue-induced cocaineseeking behavior. $J$ Neurosci 33:9319-9327.

Foster JA and McVey Neufeld KA (2013) Gut-brain axis: how the microbiome influences anxiety and depression. Trends Neurosci 36:305-312.

Franklin CL and Ericsson AC (2017) Microbiota and reproducibility of rodent models. Lab Anim (NY) 46:114-122.

Freet CS and Lawrence AL (2015) Ceftriaxone attenuates acquisition and facilitates extinction of cocaine-induced suppression of saccharin intake in C57BL/6 J mice. Physiol Behav 149:174-180.

Fujita Y, Kunitachi S, Iyo M, and Hashimoto K (2012) The antibiotic minocycline prevents methamphetamine-induced rewarding effects in mice. Pharmacol Biochem Behav 101:303-306.

Gagliano H, Delgado-Morales R, Sanz-Garcia A, and Armario A (2014) High doses of the histone deacetylase inhibitor sodium butyrate trigger a stress-like response. Neuropharmacology 79:75-82.

Gajbhiye SV, Tripathi RK, Petare A, Potey AV, and Shankar A (2018) Minocycline in alcohol withdrawal induced anxiety and alcohol relapse in rats. Curr Clin Pharmacol 13:65-72.

Gajbhiye SV, Tripathi RK, Salve B, Petare A, and Potey AV (2017) Evaluation of effect of minocycline on rewarding potential and alcohol relapse in place preference model in mice. Neurosci Lett 649:28-33.

Garcia-Keller C, Kupchik YM, Gipson CD, Brown RM, Spencer S, Bollati F, Esparza MA, Roberts-Wolfe DJ, Heinsbroek JA, Bobadilla AC, et al. (2016) Glutamatergic mechanisms of comorbidity between acute stress and cocaine self-administration. Mol Psychiatry 21:1063-1069.

Garcia EJ, Arndt DL, and Cain ME (2019) Dynamic interactions of ceftriaxone and environmental variables suppress amphetamine seeking. Brain Res 1712:63-72.

Garrido-Mesa N, Zarzuelo A, and Gálvez J (2013) Minocycline: far beyond an antibiotic. Br J Pharmacol 169:337-352.

Giménez-Gómez P, Pérez-Hernández M, Gutiérrez-López MD, Vidal R, Abuin-Martínez C, O'Shea E, and Colado MI (2018) Increasing kynurenine brain levels reduces ethanol consumption in mice by inhibiting dopamine release in nucleus accumbens. Neuropharmacology 135:581-591.

Godino A, Jayanthi S, and Cadet JL (2015) Epigenetic landscape of amphetamine and methamphetamine addiction in rodents. Epigenetics 10:574-580.

Gomez A, Luckey D, Yeoman CJ, Marietta EV, Berg Miller ME, Murray JA, White $\mathrm{BA}$, and Taneja V (2012) Loss of sex and age driven differences in the gut microbiome characterize arthritis-susceptible 0401 mice but not arthritis-resistant 0402 mice. PLoS One 7:e36095.

Goodrich JK, Di Rienzi SC, Poole AC, Koren O, Walters WA, Caporaso JG, Knight R, and Ley RE (2014) Conducting a microbiome study. Cell 158:250-262.

Goodwani S, Rao PS, Bell RL, and Sari Y (2015) Amoxicillin and amoxicillin/clavulanate reduce ethanol intake and increase GLT-1 expression as well as AKT phosphorylation in mesocorticolimbic regions. Brain Res 1622:397-408.

Gregorowski C, Seedat S, and Jordaan GP (2013) A clinical approach to the assessment and management of co-morbid eating disorders and substance use disorders. BMC Psychiatry 13:289.

Griffin EA Jr, Melas PA, Zhou R, Li Y, Mercado P, Kempadoo KA, Stephenson S, Colnaghi L, Taylor K, Hu MC, et al. (2017) Prior alcohol use enhances vulnerability to compulsive cocaine self-administration by promoting degradation of HDAC4 and HDAC5. Sci Adv 3:e1701682.

Guo Y, Wang Z, Chen L, Tang L, Wen S, Liu Y, and Yuan J (2018) Diet induced maternal obesity affects offspring gut microbiota and persists into young adulthood. Food Funct 9:4317-4327.

Habibi-Asl B, Vaez H, Najafi M, Bidaghi A, and Ghanbarzadeh S (2014) Attenuation of morphine-induced dependence and tolerance by ceftriaxone and amitriptyline in mice. Acta Anaesthesiol Taiwan 52:163-168.

Hakami AY, Alshehri FS, Althobaiti YS, and Sari Y (2017) Effects of orally administered Augmentin on glutamate transporter 1, cystine-glutamate exchanger expression and ethanol intake in alcohol-preferring rats. Behav Brain Res 320:316-322.

Hakami AY and Sari Y (2017) $\beta$-Lactamase inhibitor, clavulanic acid, attenuates ethanol intake and increases glial glutamate transporters expression in alcohol preferring rats. Neurosci Lett 657:140-145

Hakkak R, Korourian S, Foley SL, and Erickson BD (2017) Assessment of gut microbiota populations in lean and obese Zucker rats. PLoS One 12:e0181451.

Hamady M and Knight R (2009) Microbial community profiling for human microbiome projects: tools, techniques, and challenges. Genome Res 19:1141-1152.

Hammad AM, Alasmari F, Althobaiti YS, and Sari Y (2017) Modulatory effects of Ampicillin/Sulbactam on glial glutamate transporters and metabotropic glutamate receptor 1 as well as reinstatement to cocaine-seeking behavior. Behav Brain Res 332:288-298.

Han W, Tellez LA, Perkins MH, Perez IO, Qu T, Ferreira J, Ferreira TL, Quinn D, Liu ZW, Gao XB, et al. (2018) A neural circuit for gut-induced reward. Cell 175: 665-678.e23.

Harkness JH, Hitzemann RJ, Edmunds S, and Phillips TJ (2013) Effects of sodium butyrate on methamphetamine-sensitized locomotor activity. Behav Brain Res 239 139-147. 
Hasebe K, Rivera LR, Smith CM, Allnutt T, Crowley T, Nelson TM, Dean OM, McGee SL, Walder K, and Gray L (2019) Modulation of high fat diet-induced microbiome changes, but not behaviour, by minocycline. Brain Behav Immun 82:309-318.

Hillemacher T, Bachmann O, Kahl KG, and Frieling H (2018) Alcohol, microbiome, and their effect on psychiatric disorders. Prog Neuropsychopharmacol Biol Psychiatry 85:105-115.

Hills RD Jr, Pontefract BA, Mishcon HR, Black CA, Sutton SC, and Theberge CR (2019) Gut microbiome: profound implications for diet and disease. Nutrients 11: $1-40$

Hitchcock LN, Raybuck JD, Wood MA, and Lattal KM (2019) Effects of a histone deacetylase 3 inhibitor on extinction and reinstatement of cocaine selfadministration in rats. Psychopharmacology (Berl) 236:517-529.

Holota Y, Dovbynchuk T, Kaji I, Vareniuk I, Dzyubenko N, Chervinska T, Zakordonets L, Stetska V, Ostapchenko L, Serhiychuk T, et al. (2019) The long-term consequences of antibiotic therapy: role of colonic short-chain fatty acids (SCFA) system and intestinal barrier integrity. PLoS One 14:e0220642.

Host L, Anglard P, Romieu P, Thibault C, Dembele D, Aunis D, and Zwiller J (2010) Inhibition of histone deacetylases in rats self-administering cocaine regulates lissencephaly gene- 1 and reelin gene expression, as revealed by microarray technique. $J$ Neurochem 113:236-247.

Hullar MA and Fu BC (2014) Diet, the gut microbiome, and epigenetics. Cancer $J$ 20: 170-175

Hutchinson MR, Northcutt AL, Chao LW, Kearney JJ, Zhang Y, Berkelhammer DL, Loram LC, Rozeske RR, Bland ST, Maier SF, et al. (2008) Minocycline suppresses morphine-induced respiratory depression, suppresses morphine-induced reward, and enhances systemic morphine-induced analgesia. Brain Behav Immun 22: $1248-1256$

Huuskonen J, Suuronen T, Nuutinen T, Kyrylenko S, and Salminen A (2004) Regulation of microglial inflammatory response by sodium butyrate and short-chain fatty acids. $\mathrm{Br} J$ Pharmacol 141:874-880.

Hylander BL and Repasky EA (2019) Temperature as a modulator of the gut microbiome: what are the implications and opportunities for thermal medicine? Int $J$ Hyperthermia 36 (Suppl 1):83-89.

Ianiro G, Tilg H, and Gasbarrini A (2016) Antibiotics as deep modulators of gut microbiota: between good and evil. Gut 65:1906-1915.

Itzhak Y, Liddie S, and Anderson KL (2013) Sodium butyrate-induced histone acetylation strengthens the expression of cocaine-associated contextual memory. Neurobiol Learn Mem 102:34-42.

Jadhav KS, Peterson VL, Halfon O, Ahern G, Fouhy F, Stanton C, Dinan TG, Cryan JF, and Boutrel B (2018) Gut microbiome correlates with altered striatal dopamine receptor expression in a model of compulsive alcohol seeking. Neuropharmacology 141:249-259.

Jašarević E, Morrison KE, and Bale TL (2016) Sex differences in the gut microbiomebrain axis across the lifespan. Philos Trans R Soc Lond B Biol Sci 371:20150122.

Jeanblanc J, Lemoine S, Jeanblanc V, Alaux-Cantin S, and Naassila M (2015) The class I-specific HDAC inhibitor MS-275 decreases motivation to consume alcohol and relapse in heavy drinking rats. Int $J$ Neuropsychopharmacol 18:1-9.

Jing L, Luo J, Zhang M, Qin WJ, Li YL, Liu Q, Wang YT, Lawrence AJ, and Liang JH (2011) Effect of the histone deacetylase inhibitors on behavioural sensitization to a single morphine exposure in mice. Neurosci Lett 494:169-173.

Johnson SM, Saint John BE, and Dine AP (2008) Local anesthetics as antimicrobial agents: a review. Surg Infect (Larchmt) 9:205-213.

Juarez B and Han M-H (2016) Diversity of dopaminergic neural circuits in response to drug exposure. Neuropsychopharmacology 41:2424-2446.

Kalda A, Heidmets LT, Shen HY, Zharkovsky A, and Chen JF (2007) Histone deacetylase inhibitors modulates the induction and expression of amphetamineinduced behavioral sensitization partially through an associated learning of the environment in mice. Behav Brain Res 181:76-84.

Kalivas PW (2004) Glutamate systems in cocaine addiction. Curr Opin Pharmacol 4: $23-29$

Kalivas PW (2009) The glutamate homeostasis hypothesis of addiction. Nat Rev Neurosci 10:561-572.

Kalivas PW, Lalumiere RT, Knackstedt L, and Shen H (2009) Glutamate transmission in addiction. Neuropharmacology 56 (Suppl 1):169-173.

Kanarek RB, Mathes WF, and Przypek J (1996) Intake of dietary sucrose or fat reduces amphetamine drinking in rats. Pharmacol Biochem Behav 54:719-723.

Kang M, Mischel RA, Bhave S, Komla E, Cho A, Huang C, Dewey WL, and Akbarali HI (2017) The effect of gut microbiome on tolerance to morphine mediated antinociception in mice. Sci Rep 7:42658.

Kennedy PJ, Cryan JF, Dinan TG, and Clarke G (2017) Kynurenine pathway metabolism and the microbiota-gut-brain axis. Neuropharmacology 112:399-412.

Kennedy PJ, Feng J, Robison AJ, Maze I, Badimon A, Mouzon E, Chaudhury D, Damez-Werno DM, Haggarty SJ, Han MH, et al. (2013) Class I HDAC inhibition blocks cocaine-induced plasticity by targeted changes in histone methylation. Nat Neurosci 16:434-440.

Kim D, Hofstaedter CE, Zhao C, Mattei L, Tanes C, Clarke E, Lauder A, Sherrill-Mix S, Chehoud C, Kelsen J, et al. (2017) Optimizing methods and dodging pitfalls in microbiome research. Microbiome 5:52.

Kim J, John J, Langford D, Walker E, Ward S, and Rawls SM (2016) Clavulanic acid enhances glutamate transporter subtype I (GLT-1) expression and decreases reinforcing efficacy of cocaine in mice. Amino Acids 48:689-696.

Kim S and Jazwinski SM (2018) The gut microbiota and healthy aging: a minireview. Gerontology 64:513-520.

Kim SW, Hooker JM, Otto N, Win K, Muench L, Shea C, Carter P, King P, Reid AE Volkow ND, et al. (2013) Whole-body pharmacokinetics of HDAC inhibitor drugs, butyric acid, valproic acid and 4-phenylbutyric acid measured with carbon-11 labeled analogs by PET. Nucl Med Biol 40:912-918.

Kiraly DD, Walker DM, Calipari ES, Labonte B, Issler O, Pena CJ, Ribeiro EA, Russo SJ, and Nestler EJ (2016) Alterations of the host microbiome affect behavioral responses to cocaine. Sci Rep 6:35455.
Knackstedt LA and Kalivas PW (2009) Glutamate and reinstatement. Curr Opin Pharmacol 9:59-64.

Knackstedt LA, Melendez RI, and Kalivas PW (2010) Ceftriaxone restores glutamate homeostasis and prevents relapse to cocaine seeking. Biol Psychiatry 67:81-84.

Koob GF and Nestler EJ (1997) The neurobiology of drug addiction. $J$ Neuropsychiatry Clin Neurosci 9:482-497.

Koob GF and Volkow ND (2016) Neurobiology of addiction: a neurocircuitry analysis. Lancet Psychiatry 3:760-773.

Kosnicki KL, Penprase JC, Cintora P, Torres PJ, Harris GL, Brasser SM, and Kelley ST (2019) Effects of moderate, voluntary ethanol consumption on the rat and human gut microbiome. Addict Biol 24:617-630.

Kreek MJ, Levran O, Reed B, Schlussman SD, Zhou Y, and Butelman ER (2012) Opiate addiction and cocaine addiction: underlying molecular neurobiology and genetics. J Clin Invest 122:3387-3393.

Labrecque MT, Malone D, Caldwell KE, and Allan AM (2015) Impact of ethanol and saccharin on fecal microbiome in pregnant and non-pregnant mice. $J$ Pregnancy Child Health 2:1-14.

LaCrosse AL, Hill K, and Knackstedt LA (2016) Ceftriaxone attenuates cocaine relapse after abstinence through modulation of nucleus accumbens AMPA subunit expression. Eur Neuropsychopharmacol 26:186-194.

LaCrosse AL, O'Donovan SM, Sepulveda-Orengo MT, McCullumsmith RE, Reissner KJ, Schwendt M, and Knackstedt LA (2017) Contrasting the role of xCT and GLT-1 upregulation in the ability of ceftriaxone to attenuate the cue-induced reinstatement of cocaine seeking and normalize AMPA receptor subunit expression. $J$ Neurosci 37:5809-5821.

Le Bastard Q, Al-Ghalith GA, Grégoire M, Chapelet G, Javaudin F, Dailly E, Batard E, Knights D, and Montassier E (2018) Systematic review: human gut dysbiosis induced by non-antibiotic prescription medications. Aliment Pharmacol Ther 47: 332-345.

Leclercq S, Matamoros S, Cani PD, Neyrinck AM, Jamar F, Stärkel P, Windey K, Tremaroli V, Bäckhed F, Verbeke K, et al. (2014) Intestinal permeability, gutbacterial dysbiosis, and behavioral markers of alcohol-dependence severity. Proc Natl Acad Sci USA 111:E4485-E4493.

Leclercq S, Stärkel P, Delzenne NM, and de Timary P (2019) The gut microbiota: a new target in the management of alcohol dependence? Alcohol 74:105-111.

Lee K, Vuong HE, Nusbaum DJ, Hsiao EY, Evans CJ, and Taylor AMW (2018) The gut microbiota mediates reward and sensory responses associated with regimenselective morphine dependence. Neuropsychopharmacology 43:2606-2614.

Legastelois R, Botia B, and Naassila M (2013) Blockade of ethanol-induced behavioral sensitization by sodium butyrate: descriptive analysis of gene regulations in the striatum. Alcohol Clin Exp Res 37:1143-1153.

Leigh SJ, Kaakoush NO, Westbrook RF, and Morris MJ (2020) Minocycline-induced microbiome alterations predict cafeteria diet-induced spatial recognition memory impairments in rats. Transl Psychiatry 10:92.

Lemieux AM, Li B, and al'Absi M (2015) Khat use and appetite: an overview and comparison of amphetamine, khat and cathinone. J Ethnopharmacol 160:78-85.

Liu X, Cao S, and Zhang X (2015) Modulation of gut microbiota-brain axis by probiotics, prebiotics, and diet. J Agric Food Chem 63:7885-7895.

Logan CN, Bechard AR, Hamor PU, Wu L, Schwendt M, and Knackstedt LA (2020) Ceftriaxone and mGlu2/3 interactions in the nucleus accumbens core affect the reinstatement of cocaine-seeking in male and female rats. Psychopharmacology (Berl) 237:2007-2018.

Logan CN, LaCrosse AL, and Knackstedt LA (2018) Nucleus accumbens GLT-1a overexpression reduces glutamate efflux during reinstatement of cocaine-seeking but is not sufficient to attenuate reinstatement. Neuropharmacology 135:297-307.

Luo X, Pan Z, Luo S, Liu Q, Huang S, Yang G, Nong F, Fu Y, Deng X, and Zhou L (2018) Effects of ceftriaxone-induced intestinal dysbacteriosis on regulatory $\mathrm{T}$ cells validated by anaphylactic mice. Int Immunopharmacol 60:221-227.

Luo X, Zheng Y, Wen R, Deng X, Zhou L, and Liao H (2016) Effects of ceftriaxone induced intestinal dysbacteriosis on lymphocytes in different tissues in mice. Immunobiology 221:994-1000.

Maier L, Pruteanu M, Kuhn M, Zeller G, Telzerow A, Anderson EE, Brochado AR, Fernandez KC, Dose H, Mori H, et al. (2018) Extensive impact of non-antibiotic drugs on human gut bacteria. Nature 555:623-628.

Malvaez M, McQuown SC, Rogge GA, Astarabadi M, Jacques V, Carreiro S, Rusche JR, and Wood MA (2013) HDAC3-selective inhibitor enhances extinction of cocaine-seeking behavior in a persistent manner. Proc Natl Acad Sci USA 110: $2647-2652$

Malvaez M, Sanchis-Segura C, Vo D, Lattal KM, and Wood MA (2010) Modulation of chromatin modification facilitates extinction of cocaine-induced conditioned place preference. Biol Psychiatry 67:36-43.

Markle JG, Frank DN, Mortin-Toth S, Robertson CE, Feazel LM, Rolle-Kampczyk U, von Bergen M, McCoy KD, Macpherson AJ, and Danska JS (2013) Sex differences in the gut microbiome drive hormone-dependent regulation of autoimmunity. Science 339:1084-1088.

Martinez JM, Groot JA, Curtis DC, Allison CL, Marquardt PC, Holmes AN, Edwards DS, Trotter DR, Syapin PJ, Finn DA, et al. (2016) Effective reduction of acute ethanol withdrawal by the tetracycline derivative, tigecycline, in female and male DBA/2j mice. Alcohol Clin Exp Res 40:2499-2505.

Mayer EA (2011) Gut feelings: the emerging biology of gut-brain communication. Nat Rev Neurosci 12:453-466.

Mayer EA, Tillisch K, and Gupta A (2015) Gut/brain axis and the microbiota. J Clin Invest 125:926-938.

McGuire BA, Baladi MG, and France CP (2011) Eating high-fat chow enhances sensitization to the effects of methamphetamine on locomotion in rats. Eur $J$ Pharmacol 658:156-159.

McKenzie C, Tan J, Macia L, and Mackay CR (2017) The nutrition-gut microbiomephysiology axis and allergic diseases. Immunol Rev 278:277-295.

Meckel KR and Kiraly DD (2019) A potential role for the gut microbiome in substance use disorders. Psychopharmacology (Berl) 236:1513-1530. 
Mehri S, Sajjadi SS, Tabatabai SM, and Hosseinzadeh H (2018) Effects of clavulanic acid on the acquisition and reinstatement following morphine-induced conditioned place preference in mice. Basic Clin Neurosci 9:289-296.

Meng X, Zhang G, Cao H, Yu D, Fang X, de Vos WM, and Wu H (2020) Gut dysbacteriosis and intestinal disease: mechanism and treatment. J Appl Microbiol 129:787-805

Miao Z, Cheng R, Zhang Y, Liang H, Jiang F, Shen X, Chen G, Zhang Q, He F, and Li $\mathrm{M}$ (2020) Antibiotics can cause weight loss by impairing gut microbiota in mice and the potent benefits of lactobacilli. Biosci Biotechnol Biochem 84:411-420.

Milanesi LH, Rossato DR, Dias VT, Kronbauer M, D'avila LF, Somacal S, Duarte T, Duarte MMF, Emanuelli T, and Burger ME (2019) Mediterranean X Western based diets: opposite influences on opioid reinstatement. Toxicol Lett 308:7-16.

Möller T, Bard F, Bhattacharya A, Biber K, Campbell B, Dale E, Eder C, Gan L, Garden GA, Hughes ZA, et al. (2016) Critical data-based re-evaluation of minocycline as a putative specific microglia inhibitor. Glia 64:1788-1794.

Morales L, Del Olmo N, Valladolid-Acebes I, Fole A, Cano V, Merino B, Stucchi P, Ruggieri D, López L, Alguacil LF, et al. (2012) Shift of circadian feeding pattern by high-fat diets is coincident with reward deficits in obese mice. PLoS One 7:e36139.

Morganstern I, Lukatskaya O, Moon SH, Guo WR, Shaji J, Karatayev O, and Leibowitz SF (2013) Stimulation of nicotine reward and central cholinergic activity in Sprague-Dawley rats exposed perinatally to a fat-rich diet. Psychopharmacology (Berl) 230:509-524.

Mutlu EA, Gillevet PM, Rangwala H, Sikaroodi M, Naqvi A, Engen PA, Kwasny M, Lau CK, and Keshavarzian A (2012) Colonic microbiome is altered in alcoholism. Am J Physiol Gastrointest Liver Physiol 302:G966-G978.

Nee J, Zakari M, Sugarman MA, Whelan J, Hirsch W, Sultan S, Ballou S, Iturrino J, and Lembo A (2018) Efficacy of treatments for opioid-induced constipation: systematic review and meta-analysis. Clin Gastroenterol Hepatol 16:1569-1584.e2.

Nestler EJ (2014) Epigenetic mechanisms of drug addiction. Neuropharmacology 76: $259-268$.

Niedzielska-Andres E, Mizera J, Sadakierska-Chudy A, Pomierny-Chamioło L, and Filip M (2019) Changes in the glutamate biomarker expression in rats vulnerable or resistant to the rewarding effects of cocaine and their reversal by ceftriaxone. Behav Brain Res 370:111945.

Ning T, Gong X, Xie L, and Ma B (2017) Gut microbiota analysis in rats with methamphetamine-induced conditioned place preference. Front Microbiol 8:1620.

Nolan-Kenney R, Wu F, Hu J, Yang L, Kelly D, Li H, Jasmine F, Kibriya MG, Parvez $\mathrm{F}$, Shaheen I, et al. (2020) The association between smoking and gut microbiome in Bangladesh. Nicotine Tob Res 22:1339-1346.

Palmisano M and Pandey SC (2017) Epigenetic mechanisms of alcoholism and stressrelated disorders. Alcohol 60:7-18.

Panagopoulos VN and Ralevski E (2014) The role of ghrelin in addiction: a review. Psychopharmacology (Berl) 231:2725-2740.

Pandey SC, Kyzar EJ, and Zhang H (2017) Epigenetic basis of the dark side of alcohol addiction. Neuropharmacology 122:74-84

Park J, Wang Q, Wu Q, Mao-Draayer Y, and Kim CH (2019) Bidirectional regulatory potentials of short-chain fatty acids and their G-protein-coupled receptors in autoimmune neuroinflammation. Sci Rep 9:8837.

Pastor V, Host L, Zwiller J, and Bernabeu R (2011) Histone deacetylase inhibition decreases preference without affecting aversion for nicotine. J Neurochem 116 636-645.

Peleg-Raibstein D, Sarker G, Litwan K, Krämer SD, Ametamey SM, Schibli R, and Wolfrum C (2016) Enhanced sensitivity to drugs of abuse and palatable foods following maternal overnutrition. Transl Psychiatry 6:e911.

Pérez-Cobas AE, Gosalbes MJ, Friedrichs A, Knecht H, Artacho A, Eismann K, Otto W, Rojo D, Bargiela R, von Bergen M, et al. (2013) Gut microbiota disturbance during antibiotic therapy: a multi-omic approach. Gut 62:1591-1601.

Perreau-Lenz S, Hoelters LS, Leixner S, Sanchis-Segura C, Hansson A, Bilbao A, and Spanagel R (2017) mPer1 promotes morphine-induced locomotor sensitization and conditioned place preference via histone deacetylase activity. Psychopharmacology (Berl) 234:1713-1724.

Peterson VL, Jury NJ, Cabrera-Rubio R, Draper LA, Crispie F, Cotter PD, Dinan TG, Holmes A, and Cryan JF (2017) Drunk bugs: chronic vapour alcohol exposure induces marked changes in the gut microbiome in mice. Behav Brain Res 323 $172-176$

Pflughoeft KJ and Versalovic J (2012) Human microbiome in health and disease. Annu Rev Pathol 7:99-122.

Philogene-Khalid HL, Simmons SJ, Muschamp JW, and Rawls SM (2017) Effects of ceftriaxone on conditioned nicotine reward in rats. Behav Pharmacol 28:485-488.

Ponomarev I, Stelly CE, Morikawa H, Blednov YA, Mayfield RD, and Harris RA (2017) Mechanistic insights into epigenetic modulation of ethanol consumption. Alcohol 60:95-101.

Puhl MD, Cason AM, Wojnicki FH, Corwin RL, and Grigson PS (2011) A history of bingeing on fat enhances cocaine seeking and taking. Behav Neurosci 125:930-942.

Qamar N, Castano D, Patt C, Chu T, Cottrell J, and Chang SL (2019) Meta-analysis of alcohol induced gut dysbiosis and the resulting behavioral impact. Behav Brain Res 376:112196.

Qrunfleh AM, Alazizi A, and Sari Y (2013) Ceftriaxone, a beta-lactam antibiotic, attenuates relapse-like ethanol-drinking behavior in alcohol-preferring rats. $J$ Psychopharmacol 27:541-549.

Rao P and Sari Y (2014a) Effectiveness of ceftriaxone treatment in preventing relapse-like drinking behavior following long-term ethanol dependence in $\mathrm{P}$ rats. $J$ Addict Res Ther 5:1-5.

Rao PS, Bell RL, Engleman EA, and Sari Y (2015a) Targeting glutamate uptake to treat alcohol use disorders. Front Neurosci 9:144.

Rao PS, Goodwani S, Bell RL, Wei Y, Boddu SH, and Sari Y (2015b) Effects of ampicillin, cefazolin and cefoperazone treatments on GLT-1 expressions in the mesocorticolimbic system and ethanol intake in alcohol-preferring rats. Neuroscience 295:164-174.

Rao PS and Sari Y (2012) Glutamate transporter 1: target for the treatment of alcohol dependence. Curr Med Chem 19:5148-5156.
Rao PS and Sari Y (2014b) Effects of ceftriaxone on chronic ethanol consumption: a potential role for $\mathrm{xCT}$ and GLT1 modulation of glutamate levels in male P rats. J Mol Neurosci 54:71-77.

Rao PS, Saternos H, Goodwani S, and Sari Y (2015c) Effects of ceftriaxone on GLT1 isoforms, xCT and associated signaling pathways in $\mathrm{P}$ rats exposed to ethanol. Psychopharmacology (Berl) 232:2333-2342.

Rasmussen B, Unterwald EM, and Rawls SM (2011) Glutamate transporter subtype 1 (GLT-1) activator ceftriaxone attenuates amphetamine-induced hyperactivity and behavioral sensitization in rats. Drug Alcohol Depend 118:484-488.

Rawls SM, Baron DA, and Kim J (2010a) Beta-lactam antibiotic inhibits development of morphine physical dependence in rats. Behav Pharmacol 21:161-164.

Rawls SM, Zielinski M, Patel H, Sacavage S, Baron DA, and Patel D (2010b) Betalactam antibiotic reduces morphine analgesic tolerance in rats through GLT-1 transporter activation. Drug Alcohol Depend 107:261-263.

Raybuck JD, McCleery EJ, Cunningham CL, Wood MA, and Lattal KM (2013) The histone deacetylase inhibitor sodium butyrate modulates acquisition and extinction of cocaine-induced conditioned place preference. Pharmacol Biochem Behav 106:109-116.

Ren M and Lotfipour S (2020) The role of the gut microbiome in opioid use. Behav Pharmacol 31:113-121.

Ren X, Ferreira JG, Zhou L, Shammah-Lagnado SJ, Yeckel CW, and de Araujo IE (2010) Nutrient selection in the absence of taste receptor signaling. J Neurosci 30: $8012-8023$

Riezzo I, Fiore C, De Carlo D, Pascale N, Neri M, Turillazzi E, and Fineschi V (2012) Side effects of cocaine abuse: multiorgan toxicity and pathological consequences. Curr Med Chem 19:5624-5646.

Ringel-Scaia VM, Qin Y, Thomas CA, Huie KE, McDaniel DK, Eden K, Wade PA, and Allen IC (2019) Maternal influence and murine housing confound impact of NLRP1 inflammasome on microbiome composition. J Innate Immun 11:416-431.

Robertson SJ, Lemire P, Maughan H, Goethel A, Turpin W, Bedrani L, Guttman DS, Croitoru K, Girardin SE, and Philpott DJ (2019) Comparison of co-housing and littermate methods for microbiota standardization in mouse models. Cell Rep $\mathbf{2 7}$ 1910-1919.e2.

Romieu P, Deschatrettes E, Host L, Gobaille S, Sandner G, and Zwiller J (2011) The inhibition of histone deacetylases reduces the reinstatement of cocaine-seeking behavior in rats. Curr Neuropharmacol 9:21-25.

Romieu P, Host L, Gobaille S, Sandner G, Aunis D, and Zwiller J (2008) Histone deacetylase inhibitors decrease cocaine but not sucrose self-administration in rats. J Neurosci 28:9342-9348.

Rothstein JD, Patel S, Regan MR, Haenggeli C, Huang YH, Bergles DE, Jin L, Dykes Hoberg M, Vidensky S, Chung DS, et al. (2005) Beta-lactam antibiotics offer neuroprotection by increasing glutamate transporter expression. Nature 433: $73-77$.

Sakata I and Sakai T (2010) Ghrelin cells in the gastrointestinal tract. Int J Pept 2010:1-7.

Sanchis-Segura C, Lopez-Atalaya JP, and Barco A (2009) Selective boosting of transcriptional and behavioral responses to drugs of abuse by histone deacetylase inhibition. Neuropsychopharmacology 34:2642-2654.

Sari Y (2013) Potential therapeutic role of glutamate transporter 1 for the treatment of alcohol dependence. OA Alcohol 1:6.

Sari Y, Franklin KM, Alazizi A, Rao PS, and Bell RL (2013a) Effects of ceftriaxone on the acquisition and maintenance of ethanol drinking in peri-adolescent and adult female alcohol-preferring (P) rats. Neuroscience 241:229-238.

Sari Y, Sakai M, Weedman JM, Rebec GV, and Bell RL (2011) Ceftriaxone, a betalactam antibiotic, reduces ethanol consumption in alcohol-preferring rats. Alcohol Alcohol 46:239-246.

Sari Y, Smith KD, Ali PK, and Rebec GV (2009) Upregulation of GLT1 attenuates cue-induced reinstatement of cocaine-seeking behavior in rats. J Neurosci 29 : 9239-9243

Sari Y, Sreemantula SN, Lee MR, and Choi DS (2013b) Ceftriaxone treatment affects the levels of GLT1 and ENT1 as well as ethanol intake in alcohol-preferring rats. $J$ Mol Neurosci 51:779-787.

Sari Y, Toalston JE, Rao PSS, and Bell RL (2016) Effects of ceftriaxone on ethanol, nicotine or sucrose intake by alcohol-preferring $(\mathrm{P})$ rats and its association with GLT-1 expression. Neuroscience 326:117-125.

Sasaki A, McGowan PO, and Erb S (2018) A study of the effects of maternal high fat diet on behavioural responses to acute and repeated administrations of cocaine in rat offspring. Neurosci Lett 673:157-162.

Savage DC (1977) Microbial ecology of the gastrointestinal tract. Annu Rev Microbiol 31:107-133.

Schmidtner AK, Slattery DA, Gläsner J, Hiergeist A, Gryksa K, Malik VA, HellmannRegen J, Heuser I, Baghai TC, Gessner A, et al. (2019) Minocycline alters behavior, microglia and the gut microbiome in a trait-anxiety-dependent manner. Transt Psychiatry 9:223.

Schroeder FA, Penta KL, Matevossian A, Jones SR, Konradi C, Tapper AR, and Akbarian S (2008) Drug-induced activation of dopamine $\mathrm{D}(1)$ receptor signaling and inhibition of class I/II histone deacetylase induce chromatin remodeling in reward circuitry and modulate cocaine-related behaviors. Neuropsychopharmacology 33:2981-2992.

Schroeder JA, Quick KF, Landry PM, and Rawls SM (2011) Glutamate transporter activation enhances nicotine antinociception and attenuates nicotine analgesic tolerance. Neuroreport 22:970-973.

Schroeder JA, Tolman NG, McKenna FF, Watkins KL, Passeri SM, Hsu AH, Shinn BR, and Rawls SM (2014) Clavulanic acid reduces rewarding, hyperthermic and locomotor-sensitizing effects of morphine in rats: a new indication for an old drug? Drug Alcohol Depend 142:41-45.

Schwendt M, Shallcross J, Hadad NA, Namba MD, Hiller H, Wu L, Krause EG and Knackstedt LA (2018) A novel rat model of comorbid PTSD and addiction reveals intersections between stress susceptibility and enhanced cocaine seeking with a role for mGlu5 receptors. Transl Psychiatry 8:209. 
Scofield MD (2018) Exploring the role of astroglial glutamate release and association with synapses in neuronal function and behavior. Biol Psychiatry 84: 778-786.

Scorza C, Piccini C, Martínez Busi M, Abin Carriquiry JA, and Zunino P (2019) Alterations in the gut microbiota of rats chronically exposed to volatilized cocaine and its active adulterants caffeine and phenacetin. Neurotox Res 35:111-121.

Seitz J, Trinh S, and Herpertz-Dahlmann B (2019) The microbiome and eating disorders. Psychiatr Clin North Am 42:93-103.

Sender R, Fuchs S, and Milo R (2016) Revised estimates for the number of human and bacteria cells in the body. PLoS Biol 14:e1002533.

Serafine KM, Bentley TA, Grenier AE, and France CP (2014) Eating high fat chow and the behavioral effects of direct-acting and indirect-acting dopamine receptor agonists in female rats. Behav Pharmacol 25:287-295.

Serafine KM, Bentley TA, Koek W, and France CP (2015) Eating high fat chow, but not drinking sucrose or saccharin, enhances the development of sensitization to the locomotor effects of cocaine in adolescent female rats. Behav Pharmacol 26: $321-325$.

Serafine KM, Labay C, and France CP (2016) Dietary supplementation with fish oil prevents high fat diet-induced enhancement of sensitivity to the locomotor stimulating effects of cocaine in adolescent female rats. Drug Alcohol Depend 165: $45-52$.

Seto E and Yoshida M (2014) Erasers of histone acetylation: the histone deacetylase enzymes. Cold Spring Harb Perspect Biol 6:a018713.

Shen HW, Scofield MD, Boger H, Hensley M, and Kalivas PW (2014) Synaptic glutamate spillover due to impaired glutamate uptake mediates heroin relapse. J Neurosci 34:5649-5657.

Shen HY, Kalda A, Yu L, Ferrara J, Zhu J, and Chen JF (2008) Additive effects of histone deacetylase inhibitors and amphetamine on histone $\mathrm{H} 4$ acetylation, cAMP responsive element binding protein phosphorylation and DeltaFosB expression in the striatum and locomotor sensitization in mice. Neuroscience 157:644-655.

Shreiner AB, Kao JY, and Young VB (2015) The gut microbiome in health and in disease. Curr Opin Gastroenterol 31:69-75.

Silva YP, Bernardi A, and Frozza RL (2020) The role of short-chain fatty acids from gut microbiota in gut-brain communication. Front Endocrinol (Lausanne) 11:25.

Simon-O'Brien E, Alaux-Cantin S, Warnault V, Buttolo R, Naassila M, and Vilpoux C (2015) The histone deacetylase inhibitor sodium butyrate decreases excessive ethanol intake in dependent animals. Addict Biol 20:676-689.

Sindberg GM, Callen SE, Banerjee S, Meng J, Hale VL, Hegde R, Cheney PD, Villinger F, Roy S, and Buch S (2019) Morphine potentiates dysbiotic microbial and metabolic shifts in acute SIV infection. J Neuroimmune Pharmacol 14:200-214.

Singh RK, Chang HW, Yan D, Lee KM, Ucmak D, Wong K, Abrouk M, Farahnik B, Nakamura M, Zhu TH, et al. (2017) Influence of diet on the gut microbiome and implications for human health. J Transl Med 15:73.

Sirohi S, Van Cleef A, and Davis JF (2017) Intermittent access to a nutritionally complete high-fat diet attenuates alcohol drinking in rats. Pharmacol Biochem Behav 153:105-115.

Snider SE, Hendrick ES, and Beardsley PM (2013) Glial cell modulators attenuate methamphetamine self-administration in the rat. Eur J Pharmacol 701:124-130.

Sofuoglu M, Mooney M, Kosten T, Waters A, and Hashimoto K (2011) Minocycline attenuates subjective rewarding effects of dextroamphetamine in humans. Psy. chopharmacology (Berl) 213:61-68.

Sofuoglu M, Waters AJ, Mooney M, and O’Malley SS (2009) Minocycline reduced craving for cigarettes but did not affect smoking or intravenous nicotine responses in humans. Pharmacol Biochem Behav 92:135-140.

Sondheimer I and Knackstedt LA (2011) Ceftriaxone prevents the induction of cocaine sensitization and produces enduring attenuation of cue- and cocaine-primed reinstatement of cocaine-seeking. Behav Brain Res 225:252-258.

Sonnenburg ED, Smits SA, Tikhonov M, Higginbottom SK, Wingreen NS, and Sonnenburg JL (2016) Diet-induced extinctions in the gut microbiota compound over generations. Nature 529:212-215.

Sonnenburg ED and Sonnenburg JL (2014) Starving our microbial self: the deleterious consequences of a diet deficient in microbiota-accessible carbohydrates. Cell Metab 20:779-786.

Spencer S, Scofield M, and Kalivas PW (2016) The good and bad news about glutamate in drug addiction. $J$ Psychopharmacol 30:1095-1098.

Spor A, Koren O, and Ley R (2011) Unravelling the effects of the environment and host genotype on the gut microbiome. Nat Rev Microbiol 9:279-290.

Stadlbauer V, Horvath A, Komarova I, Schmerboeck B, Feldbacher N, Wurm S, Klymiuk I, Durdevic M, Rainer F, Blesl A, et al. (2019) A single alcohol binge impacts on neutrophil function without changes in gut barrier function and gut microbiome composition in healthy volunteers. PLoS One 14:e0211703.

Stennett BA, Frankowski JC, Peris J, and Knackstedt LA (2017) Ceftriaxone reduces alcohol intake in outbred rats while upregulating xCT in the nucleus accumbens core. Pharmacol Biochem Behav 159:18-23.

Stennett BA, Padovan-Hernandez Y, and Knackstedt LA (2020) Sequential cocainealcohol self-administration produces adaptations in rat nucleus accumbens core glutamate homeostasis that are distinct from those produced by cocaine selfadministration alone. Neuropsychopharmacology 45:441-450.

Stilling RM, van de Wouw M, Clarke G, Stanton C, Dinan TG, and Cryan JF (2016) The neuropharmacology of butyrate: the bread and butter of the microbiota-gutbrain axis? Neurochem Int 99:110-132.

Sun J, Wang L, Jiang B, Hui B, Lv Z, and Ma L (2008) The effects of sodium butyrate, an inhibitor of histone deacetylase, on the cocaine- and sucrose-maintained selfadministration in rats. Neurosci Lett 441:72-76.

Syapin PJ, Martinez JM, Curtis DC, Marquardt PC, Allison CL, Groot JA, Baby C, Al-Hasan YM, Segura I, Scheible MJ, et al. (2016) Effective reduction in high ethanol drinking by semisynthetic tetracycline derivatives. Alcohol Clin Exp Res 40:2482-2490.

Taha SA (2010) Preference or fat? Revisiting opioid effects on food intake. Physiol Behav 100:429-437.
Tallarida CS, Corley G, Kovalevich J, Yen W, Langford D, and Rawls SM (2013) Ceftriaxone attenuates locomotor activity induced by acute and repeated cocaine exposure in mice. Neurosci Lett 556:155-159.

Tellez LA, Medina S, Han W, Ferreira JG, Licona-Limón P, Ren X, Lam TT, Schwartz GJ, and de Araujo IE (2013) A gut lipid messenger links excess dietary fat to dopamine deficiency. Science 341:800-802.

Temko JE, Bouhlal S, Farokhnia M, Lee MR, Cryan JF, and Leggio L (2017) The microbiota, the gut and the brain in eating and alcohol use disorders: a 'menage à trois'? Alcohol Alcohol 52:403-413.

Thanos PK, Kim R, Cho J, Michaelides M, Anderson BJ, Primeaux SD, Bray GA, Wang GJ, Robinson JK, and Volkow ND (2010) Obesity-resistant S5B rats showed greater cocaine conditioned place preference than the obesity-prone $\mathrm{OM}$ rats. Physiol Behav 101:713-718.

Torregrossa MM and Kalivas PW (2008) Microdialysis and the neurochemistry of addiction. Pharmacol Biochem Behav 90:261-272.

Torres-Fuentes C, Golubeva AV, Zhdanov AV, Wallace S, Arboleya S, Papkovsky DB, El Aidy S, Ross P, Roy BL, Stanton C, et al. (2019) Short-chain fatty acids and microbiota metabolites attenuate ghrelin receptor signaling. FASEB $J \mathbf{3 3}$ 13546-13559.

Townsend EA, Beloate LN, Huskinson SL, Roma PG, and Freeman KB (2015) Corn oil, but not cocaine, is a more effective reinforcer in obese than in lean Zucker rats. Physiol Behav 143:136-141.

Trantham-Davidson H, LaLumiere RT, Reissner KJ, Kalivas PW, and Knackstedt LA (2012) Ceftriaxone normalizes nucleus accumbens synaptic transmission, glutamate transport, and export following cocaine self-administration and extinction training. J Neurosci 32:12406-12410.

Tremlett H, Bauer KC, Appel-Cresswell S, Finlay BB, and Waubant E (2017) The gut microbiome in human neurological disease: a review. Ann Neurol 81:369-382.

Vengeliene V, Cannella N, Takahashi T, and Spanagel R (2016) Metabolic shift of the kynurenine pathway impairs alcohol and cocaine seeking and relapse. Psychopharmacology (Berl) 233:3449-3459.

Villavasso S, Shaw C, Skripnikova E, Shah K, Davis JF, and Sirohi S (2019) Nutritional contingency reduces alcohol drinking by altering central neurotransmitter receptor gene expression in rats. Nutrients 11:2731.

Volkow ND, Wang GJ, Tomasi D, and Baler RD (2013) Obesity and addiction: neurobiological overlaps. Obes Rev 14:2-18.

Volkow ND and Wise RA (2005) How can drug addiction help us understand obesity? Nat Neurosci 8:555-560.

Volkow ND, Wise RA, and Baler R (2017) The dopamine motive system: implications for drug and food addiction. Nat Rev Neurosci 18:741-752.

Volpe GE, Ward H, Mwamburi M, Dinh D, Bhalchandra S, Wanke C, and Kane AV (2014) Associations of cocaine use and HIV infection with the intestinal microbiota, microbial translocation, and inflammation. J Stud Alcohol Drugs 75:347-357.

Wakabayashi KT and Kiyatkin EA (2014) Critical role of peripheral drug actions in experience-dependent changes in nucleus accumbens glutamate release induced by intravenous cocaine. $J$ Neurochem 128:672-685.

Wang B, You ZB, Oleson EB, Cheer JF, Myal S, and Wise RA (2013) Conditioned contribution of peripheral cocaine actions to cocaine reward and cocaine-seeking. Neuropsychopharmacology 38:1763-1769.

Wang F, Meng J, Zhang L, Johnson T, Chen C, and Roy S (2018a) Morphine induces changes in the gut microbiome and metabolome in a morphine dependence model. Sci Rep 8:3596.

Wang F, Meng J, Zhang L, and Roy S (2020) Opioid use potentiates the virulence of hospital-acquired infection, increases systemic bacterial dissemination and exacerbates gut dysbiosis in a murine model of Citrobacter rodentium infection. Gut Microbes 11:172-190.

Wang F and Roy S (2017) Gut homeostasis, microbial dysbiosis, and opioids. Toxico Pathol 45:150-156.

Wang G, Liu Q, Guo L, Zeng H, Ding C, Zhang W, Xu D, Wang X, Qiu J, Dong Q, et al. (2018b) Gut microbiota and relevant metabolites analysis in alcohol dependent mice. Front Microbiol 9:1874.

Wang R, Li S, Jin L, Zhang W, Liu N, Wang H, Wang Z, Wei P, Li F, Yu J, et al. (2019) Four-week administration of nicotinemoderately impacts blood metabolic profile and gut microbiota in a diet-dependent manner. Biomed Pharmacother 115 108945.

Wang R, Zhang Y, Qing H, Liu M, and Yang P (2010) The extinction of morphineinduced conditioned place preference by histone deacetylase inhibition. Neurosci Lett 483:137-142.

Ward SJ, Rasmussen BA, Corley G, Henry C, Kim JK, Walker EA, and Rawls SM (2011) Beta-lactam antibiotic decreases acquisition of and motivation to respond for cocaine, but not sweet food, in C57Bl/6 mice. Behav Pharmacol 22:370-373.

Weiland A, Garcia S, and Knackstedt LA (2015) Ceftriaxone and cefazolin attenuate the cue-primed reinstatement of alcohol-seeking. Front Pharmacol 6:44.

Wellman PJ, Nation JR, and Davis KW (2007) Impairment of acquisition of cocaine self-administration in rats maintained on a high-fat diet. Pharmacol Biochem Behav 88:89-93.

Willing BP, Russell SL, and Finlay BB (2011) Shifting the balance: antibiotic effects on host-microbiota mutualism. Nat Rev Microbiol 9:233-243.

Wilson AS, Koller KR, Ramaboli MC, Nesengani LT, Ocvirk S, Chen C, Flanagan CA, Sapp FR, Merritt ZT, Bhatti F, et al. (2020) Diet and the human gut microbiome: an international review. Dig Dis Sci 65:723-740.

Wilson ID and Nicholson JK (2017) Gut microbiome interactions with drug metabolism, efficacy, and toxicity. Transl Res 179:204-222.

Wise RA and Kiyatkin EA (2011) Differentiating the rapid actions of cocaine. Nat Rev Neurosci 12:479-484.

Wise RA, Wang B, and You ZB (2008) Cocaine serves as a peripheral interoceptive conditioned stimulus for central glutamate and dopamine release. PLoS One 3 e2846.

Wiss DA (2019) A biopsychosocial overview of the opioid crisis: considering nutrition and gastrointestinal health. Front Public Health 7:193. 
Wong ML, Inserra A, Lewis MD, Mastronardi CA, Leong L, Choo J, Kentish S, Xie P, Morrison M, Wesselingh SL, et al. (2016) Inflammasome signaling affects anxietyand depressive-like behavior and gut microbiome composition. Mol Psychiatry 21 797-805.

Wu S, Yi J, Zhang YG, Zhou J, and Sun J (2015) Leaky intestine and impaired microbiome in an amyotrophic lateral sclerosis mouse model. Physiol Rep 3:1-10.

Wu Y, Wan J, Choe U, Pham Q, Schoene NW, He Q, Li B, Yu L, and Wang TTY (2019) Interactions between food and gut microbiota: impact on human health. Annu Rev Food Sci Technol 10:389-408.

Xiao HW, Ge C, Feng GX, Li Y, Luo D, Dong JL, Li H, Wang H, Cui M, and Fan SJ (2018) Gut microbiota modulates alcohol withdrawal-induced anxiety in mice. Toxicol Lett 287:23-30.

Xiao L, Feng Q, Liang S, Sonne SB, Xia Z, Qiu X, Li X, Long H, Zhang J, Zhang D, et al. (2015) A catalog of the mouse gut metagenome. Nat Biotechnol 33:1103-1108.

Xu Y, Liu X, Zhang X, Zhang G, Zhang R, Liu T, and Hao W (2012) Histone acetylation of the htr3a gene in the prefrontal cortex of Wistar rats regulates ethanolseeking behavior. Neural Regen Res 7:1021-1028.

Xu Y, Xie Z, Wang H, Shen Z, Guo Y, Gao Y, Chen X, Wu Q, Li X, and Wang K (2017) Bacterial diversity of intestinal microbiota in patients with substance use disorders revealed by 16S rRNA gene deep sequencing. Sci Rep 7:3628.

Xu Z, Wang C, Dong X, Hu T, Wang L, Zhao W, Zhu S, Li G, Hu Y, Gao Q, et al. (2019) Chronic alcohol exposure induced gut microbiota dysbiosis and its correlations with neuropsychic behaviors and brain BDNF/Gabra1 changes in mice. Biofactors 45 187-199.

Yamawaki Y, Yoshioka N, Nozaki K, Ito H, Oda K, Harada K, Shirawachi S, Asano S, Aizawa H, Yamawaki S, et al. (2018) Sodium butyrate abolishes lipopolysaccharide-induced depression-like behaviors and hippocampal microglial activation in mice. Brain Res 1680:13-38.

Yan AW, Fouts DE, Brandl J, Stärkel P, Torralba M, Schott E, Tsukamoto H, Nelson KE, Brenner DA, and Schnabl B (2011) Enteric dysbiosis associated with a mouse model of alcoholic liver disease. Hepatology 53:96-105.

Yoshiya K, Lapchak PH, Thai TH, Kannan L, Rani P, Dalle Lucca JJ, and Tsokos GC (2011) Depletion of gut commensal bacteria attenuates intestinal ischemia/reperfusion injury. Am J Physiol Gastrointest Liver Physiol 301:G1020-G1030.
Yu C, Liu S, Chen L, Shen J, Niu Y, Wang T, Zhang W, and Fu L (2019) Effect of exercise and butyrate supplementation on microbiota composition and lipid metabolism. $J$ Endocrinol 243:125-135.

Zallar LJ, Farokhnia M, Tunstall BJ, Vendruscolo LF, and Leggio L (2017) The role of the ghrelin system in drug addiction. Int Rev Neurobiol 136:89-119.

Zhang L, Meng J, Ban Y, Jalodia R, Chupikova I, Fernandez I, Brito N, Sharma U, Abreu MT, Ramakrishnan S, et al. (2019a) Morphine tolerance is attenuated in germfree mice and reversed by probiotics, implicating the role of gut microbiome. Proc Natl Acad Sci USA 116:13523-13532.

Zhang S and Chen DC (2019) Facing a new challenge: the adverse effects of antibiotics on gut microbiota and host immunity. Chin Med $J$ (Engl) 132:1135-1138.

Zhang X, Wang J, Yu T, Du D, and Jiang W (2015) Minocycline can delay the development of morphine tolerance, but cannot reverse existing tolerance in the maintenance period of neuropathic pain in rats. Clin Exp Pharmacol Physiol 42: 94-101.

Zhang X, Yasuda K, Gilmore RA, Westmoreland SV, Platt DM, Miller GM and Vallender EJ (2019b) Alcohol-induced changes in the gut microbiome and metabolome of rhesus macaques. Psychopharmacology (Berl) 236:1531-1544.

Zhernakova A, Kurilshikov A, Bonder MJ, Tigchelaar EF, Schirmer M, Vatanen T, Mujagic Z, Vila AV, Falony G, Vieira-Silva S, et al.; LifeLines cohort study (2016) Population-based metagenomics analysis reveals markers for gut microbiome composition and diversity. Science 352:565-569.

Zhou D, Pan Q, Xin FZ, Zhang RN, He CX, Chen GY, Liu C, Chen YW, and Fan JG (2017) Sodium butyrate attenuates high-fat diet-induced steatohepatitis in mice by improving gut microbiota and gastrointestinal barrier. World $J$ Gastroenterol 23 : $60-75$.

Zhou L and Xiao X (2018) The role of gut microbiota in the effects of maternal obesity during pregnancy on offspring metabolism. Biosci Rep 38:1-14.

Zhu J, Zhao N, Chen Y, Zhu L, Zhong Q, Liu J, and Chen T (2017) Sodium butyrate modulates a methamphetamine-induced conditioned place preference. $J$ Neurosci Res 95:1044-1052.

Zimmermann M, Zimmermann-Kogadeeva M, Wegmann R, and Goodman AL (2019) Mapping human microbiome drug metabolism by gut bacteria and their genes. Nature 570:462-467. 